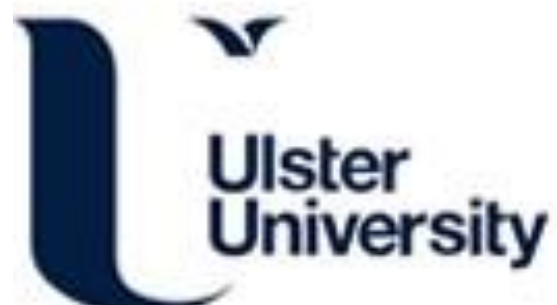

The presuppositions of soft triggers are obligatory scalar implicatures

Romoli, J. (2014). The presuppositions of soft triggers are obligatory scalar implicatures. Journal of Semantics, n/a, 1-48. https://doi.org/10.1093/jos/fft017

Link to publication record in Ulster University Research Portal

\section{Published in:}

Journal of Semantics

Publication Status:

Published (in print/issue): 01/01/2014

DOI:

10.1093/jos/fft017

\section{Document Version}

Author Accepted version

\section{General rights}

Copyright for the publications made accessible via Ulster University's Research Portal is retained by the author(s) and / or other copyright owners and it is a condition of accessing these publications that users recognise and abide by the legal requirements associated with these rights.

\section{Take down policy}

The Research Portal is Ulster University's institutional repository that provides access to Ulster's research outputs. Every effort has been made to ensure that content in the Research Portal does not infringe any person's rights, or applicable UK laws. If you discover content in the Research Portal that you believe breaches copyright or violates any law, please contact pure-support@ulster.ac.uk. 


\title{
The presuppositions of soft triggers are obligatory scalar implicatures*
}

\author{
Jacopo Romoli
}

\begin{abstract}
Presupposition triggers can be divided in two groups, 'soft' and 'hard,' based on whether the presuppositions they give rise to are easily defeasible and whether they project uniformly in quantificational sentences (Abusch 2002, 2010, Charlow 2009). Recently, two ideas have been put forward in the literature in connection to this problem. First, soft triggers should be thought of as non-presuppositional items associated with lexical alternatives (Abusch 2002, 2010). Second, the projection behavior of presuppositions can be accounted for by a theory based on scalar implicatures (Chemla 2009a, Chemla 2010). In this paper, building on these two ideas, I propose a scalar approach to the presuppositions of soft triggers. The contribution of the proposal is twofold. First, I propose a theory of soft presuppositions as scalar implicatures that provides an account of their behaviour in quantificational sentences that makes more accurate predictions than Chemla's (2009a), Chemla's (2010) and Abusch's (2010) proposals and other non-alternative-based theories that I am aware of. Second, I develop an account of the differences between soft and hard presuppositions, on the one hand, and the similarities between soft presuppositions and scalar implicatures, on the other. Finally, the proposed approach also reduces the pattern of presupposition suspension to independent principles needed in the theory of scalar implicatures.
\end{abstract}

Keywords: Presuppositions, soft presuppositions, scalar implicatures, alternatives

* For precious discussion, suggestions, and comments, I thank Márta Abrusán, Pranav Anand, Alan Bale, Chris Barker, Cory Bill, Ivano Caponigro, Emmanuel Chemla, Gennaro Chierchia, Stephen Crain, Luka Crnic, Danny Fox, Michael Franke, Jon Gajewski, Ben George, Irene Heim, Larry Horn, Nathan Klinedinst, Clemens Mayr, Giorgio Magri, Marie-Christine Meyer, Bernhard Nickel, Andreea Nicolae, Dan Lassiter, Hazel Pearson, Craige Roberts, Yael Sharvit, Raj Singh, Greg Scontras, Bob Stalnaker, Yasutada Sudo and Kai von Fintel. The paper has also greatly benefited from the criticisms, suggestions, and comments of the editor Robert van Rooij and the anonymous referees. Remaining errors are of course mine. 


\section{Introduction}

Traditionally presupposition triggers have been treated uniformly. ${ }^{1}$ The standard architecture of presupposition theories has the following shape: there is a set of expressions and constructions like those in (1), which trigger inferences with a common characteristic behaviour in complex sentences.

$$
\{\text { stop, win, also, discover, it-clefts, again ...\} }
$$

This assumption of uniformity covers a lot of empirical ground, because these inferences do behave uniformly when their corresponding triggers are embedded in connectives, modals, and questions. As an example, consider win: a sentence with win like (2a), its negation in (2b), its questioned version in (2c), and a conditional or a possibility modal embedding (2a) like (2d) and (2e), all give rise to the inference in (2f). Or, in traditional terminology, the inference of (2a) in (2f) 'projects' through embeddings when (2a) is embedded under negation, a question operator, a possibility modal, or in the antecedent of a conditional.
a. Bill won the marathon.
b. Bill didn't win the marathon.
c. Did Bill win the marathon?
d. It's possible that Bill won the marathon.
e. If Bill won the marathon, he will celebrate tonight.
f. $\rightsquigarrow$ Bill participated in the marathon.

If we take any other expression in the set of presuppositional triggers in (1), we can reproduce the same projective behaviour. For instance, if we consider it-clefts, we can see that each of (3a)-(3e) gives rise to the inference in (3f) in the same way.
a. It is Mary who broke that computer.
b. It isn't Mary who broke that computer.
c. Is it Mary who broke that computer?
d. It's possible that it is Mary who broke that computer.
e. If it is Mary who broke that computer, she should repair it.
f. Somebody broke that computer.

I will call this uniform aspect of the behaviour of presuppositional triggers the 'similarity problem,' as summarised in (4).

(4) The similarity problem: presuppositions behave uniformly in their projection behaviour through propositional connectives, modals, and questions.

1 See Heim 1983, Beaver 2001, van der Sandt 1992, Geurts 1999 among many others. 
The presuppositions of soft triggers are obligatory scalar implicatures

Despite their similarity, however, as discussed since Karttunen 1971 and Stalnaker 1974 , there appear to be differences in the behaviour of certain triggers. ${ }^{2}$ In particular, two main differences have been observed in the literature, descriptively dividing the set of triggers in two classes, usually referred to as 'soft' and 'hard' triggers (Abusch 2002, 2010).

The first difference has to do with the ease of suspension of the presupposition associated to some triggers. This can be brought about via what Simons (2001) calls "the explicit ignorance test." The recipe for this test is as follows: create a context in which the speaker is evidently ignorant about the presupposition; those triggers that do not give rise to infelicity in such contexts are soft triggers. Consider the following two examples modeled on Abusch 2010 that show that according to this diagnostic win and it-clefts are soft and hard triggers respectively. ${ }^{3,4}$

2 see also Chierchia \& McConnell-Ginet 2000, Simons 2001, Abusch 2002, 2010, Abbott 2006 and Klinedinst 2010 among others.

3 Notice that the speaker does not need to say explicitly that she is ignorant about the presupposition, if it is clear from the context that she is. Consider the following example in (i) and assume it is a conversation between two people who are meeting for the first time (from Geurts 1995 reported in Simons 2001): the presupposition of stop, i.e. that the addressee used to smoke, is clearly not present.

(i) I noticed that you keep chewing on your pencil. Have you recently stopped smoking?

4 The boundaries of the soft vs. hard distinction are not uncontroversial (see Abbott 2006 and Klinedinst 2010 for discussion). There are two main controversial cases: the first case is the status of definite descriptions or possessives, which in some cases like (i) appear to behave like soft triggers, while in others like (ii) they do not (thanks to an anonymous reviewer for pointing this case out to me).

(i) I do not know if Jane has a brother, but if that guy she came in with is her brother the party will be fun

(ii) I don't know if Jane has a brother, \#but if her brother comes tonight the party will be fun

The distinction between (i) and (ii) might be traced back to a difference between argumental and predicative positions (cf. Doron 1983; see also von Fintel 2004). In the following, I put aside these controversial cases, and focus on paradigmatic cases like win and stop.

The second case regards some apparent differences among factive predicates. Karttunen (1971) observes that discover and regret pattern differently in cases like (iiia) and (iiib) (from Karttunen 1971): the presupposition that I didn't tell the truth is suspended in (iiia) but appears to go through in (iiib).

(iii) a. If I discover later that I have not told the truth, I will confess it to everyone.

b. If I regret later that I have not told the truth, I will confess it to everyone.

Karttunen (1971) proposes to distinguish between two different classes of factives. Stalnaker (1974) argues that the difference between cases like (iiia) and (iiib) can, instead, be given a pragmatic explanation. I ignore this issue here and treat all factives uniformly as soft triggers. Notice that the present proposal is compatible with a pragmatic explanation à la Stalnaker (1974), which can provide 
(5) I don't know whether Bill ended up participating in the Marathon yesterday. But if he won, he will celebrate tonight.

(6) I don't know whether anybody broke that computer. \#But if it is Mary who did it, she should repair it.

The second difference has to do with the projection behaviour in quantificational sentences. While as we saw the presuppositions of soft and hard triggers ('soft' and 'hard presuppositions' henceforth) appear to pattern alike with respect to the projection behavior when embedded in connectives, modals, and questions as shown by the cases in (2) and (3) above, they behave differently when embedded in quantificational sentences (Charlow 2009; see also Fox 2012). The gist of the observation, due to Charlow (2009), is that while hard presuppositions appear to project uniformly universally in quantificational sentences, the force of the projection inference of soft presuppositions depends on the quantifier involved. So, for instance, if we consider also, which patterns with hard-triggers like it-clefts in explicit ignorance contexts, we observe that all of (7a)-(7d) give rise to the universal inference in (7e).
a. Each of these students also smokes [Marlboros $]_{F}$.
b. None of these students also smokes [Marlboros $]_{F}$.
c. More/Less than three of these students also smoke [Marlboros] $]_{F}$.
d. Some of these students also smokes [Marlboros $]_{F}$.
e. $\rightsquigarrow$ Each of these students smokes something other than Marlboro.

On the other hand, when we turn to stop, which patterns with win in the suspension contexts above, we find a non-uniform behaviour depending on the quantifier involved. In other words, while (8a) and (8b) give rise to (8c), (9a) and (9b) do not give rise to the analogous inference $(9 \mathrm{c})$. This pattern has also been shown experimentally by Chemla (2009a,b), I will come back to it in detail.

(8) a. Each of these students stopped smoking.

b. None of these students stopped smoking.

c. $\rightsquigarrow$ Each of these students used to smoke.

(9) a. More/Less than three of these students stopped smoking.

b. Some of these students stopped smoking.

c. $\quad \not \rightarrow$ Each of these students used to smoke.

In sum, these two differences in suspension and in projection constitute what I will call the 'difference problem'.

a source of difference among factives. 
The presuppositions of soft triggers are obligatory scalar implicatures

(10) The difference problem: certain presuppositions behave differently than others with respect to their ease of suspension and their projection behaviour in quantificational sentences.

(10) calls for dividing the set of triggers in two groups: the soft ones, like win, stop, discover among others, which give rise to suspendable presuppositions and do not project uniformly universally in quantificational sentences, and the class of hard ones, like it-clefts, also, again, which, instead, are not suspendable and project uniformly in quantificational sentences, regardless of the quantifier involved.

The tension between the difference and the similarity problems constitutes a serious challenge to any presupposition theory. This is because, on the one hand, we want to explain the differences in suspension and projection, but on the other we want to maintain an account of their similarities. Recently, Abusch $(2002,2010)$ has proposed a radical solution: giving up the idea that soft presuppositions are presuppositions in the traditional sense. Rather, they would arise as pragmatic inferences over alternatives. In this approach, the similarity between soft and hard presuppositions is no more than a coincidence, which gives us the appearance of uniformity between the two. As we will see, in this way she can account for the ease of suspension of soft presuppositions. However, I will show that her system falls short in accounting for the difference in projection between soft and hard presuppositions and has further empirical and conceptual problems, linked to the way in which she accounts for the similarity problem.

Chemla 2009a takes the alternative-based account a step further and proposes that presuppositional triggers are strong scalar terms like every and that all presuppositions should be accounted for by a theory of scalar implicatures (an idea then 
developed in Chemla 2010). ${ }^{5,6}$ Chemla 2009a and Chemla 2010, however, treat all triggers uniformly, therefore automatically addressing the similarity problem, but leaving the difference problem unanswered. Moreover, as I will show, they make some wrong predictions in the case of quantificational sentences.

Building on Romoli 2011, I develop Chemla's (2009a) scalar approach, however not applied to presuppositions in general, but only to soft presuppositions, along the lines of Abusch (2010). The contribution of the proposal is twofold. First, I propose a theory of soft presuppositions as scalar implicatures that provides an account of their behaviour in quantificational sentences that makes more accurate predictions than Chemla's (2009a), Chemla's (2010) and Abusch's (2010) proposals and other non-alternative-based theories that I am aware of. Second, I develop an account of the differences between soft and hard presuppositions, on the one hand, and the similarities between soft presuppositions and scalar implicatures, on the other. ${ }^{7}$ The paper is organized as follows: in section 2, I sketch the proposals by Abusch

5 While these ideas have been present in the literature in one form or other for a while, it is only recently that these ideas have taken sufficiently formally precise forms in the works of Abusch (2002, 2010) and Chemla (2009a, 2010). The observation that certain triggers appears to be more easily suspendable than others goes back to a discussion between Karttunen (1971) and Stalnaker (1974) about apparent differences between factive verbs (cf. fn. 3). Stalnaker (1974) is also one of the first to explore the role of implicatures in the suspension of presuppositions, by proposing that the differences between triggers could in fact be accounted for by taking into consideration general conversational principles. Gazdar (1979) develops a theory of presuppositions in which implicatures play a crucial role in the projection/non-projection of presuppositions, and Soames (1979), in a different way, also maintains the idea that implicatures play a role in the non-projection of presuppositions. More recently, Beaver (2010) proposes that the relevant factor in soft presupposition suspension is intonation, rather than implicatures. See, however, Wagner 2012: pp.8-9 for some challenging examples for this idea. Other recent accounts of the soft-hard trigger distinction are Simons 2001, Abbott 2006 and Klinedinst 2010. I don't discuss their attempts here for lack of space; for detailed criticism of Simons's (2001) proposal, see Abrusán 2011a. Abbott (2006) herself points out some empirical problems for her proposal. I leave the comparison with Klinedinst's (2010) account for further research. Finally, the attempt of reducing the projection of presuppositions to implicatures can be traced back to Kempson 1975 and Wilson 1975 (see Soames 1979 for a critical assessment).

6 A bibliographic note: Chemla 2009a is an unpublished previous version of Chemla 2009b, which contains a discussion of the main idea about presupposition projection as a scalar phenomenon. Both report the experimental results about presuppositions in quantificational sentences. In the following, I will refer to Chemla 2009a for the main idea about scalar projection and to both for the experimental results. Chemla 2010 is a development of Chemla's (2009a) idea, but in a completely novel unified approach to scalar implicatures and presuppositions, that I will sketch in some detail in Appendix A.

7 The overarching goal of Romoli 2011 was to show that in this way we can account for some puzzling cases of the interaction between soft presuppositions and "regular" scalar implicatures (see also Romoli 2012: chapter 3). In Romoli 2012: chapter 4, I also apply this approach to account for the intervention of soft presuppositions in the licensing of NPIs. In Romoli (to appear), I propose a similar approach to neg-raising inferences. 
The presuppositions of soft triggers are obligatory scalar implicatures

(2002, 2010) and Chemla (2009a). In section 3, I outline the implementation of the proposal and its first predictions. In section 4 , I discuss the novel predictions for quantificational sentences. In section 5, I show how to account for the differences between soft and hard presuppositions, on the one hand, and soft presuppositions and scalar implicatures, on the other. I conclude the paper in section 6. In appendix A, I draw a more detailed comparison with Chemla's (2010) proposal, and in appendix B with Fox's (2012) more conservative approaches to the similarity and difference problems. In appendix C, I sketch another way if thinking about the soft-hard distinction building on Rooij $(2005,2010)$.

\section{Alternatives and projection}

\subsection{Abusch (2002, 2010): soft triggers and lexical alternatives}

Abusch $(2002,2010)$ proposes a non-presuppositional account of soft presuppositions based on lexical alternatives and a pragmatic principle of disjunctive closure. The defeasibility of soft presuppositions would come from the context sensitivity of this pragmatic principle. In slightly more detail, she assumes that the alternatives of soft triggers are intuitively contrastive terms, so that, for instance, win and lose are alternatives to each other. These lexical alternatives grow compositionally into sentential alternatives (Rooth 1992, Chierchia 2004 a.o.). For instance (11a) has the alternatives in (11b).

a. Bill won.

b. $\mathscr{A} l t=\{\operatorname{won}(b), \operatorname{lost}(b)\}$

In addition to the alternatives, Abusch (2010) assumes a pragmatic principle, which requires the disjunction of the set of alternatives, indicated as $\vee \mathscr{A} l t$, to be true. Given the alternatives assumed, their disjunction entails what is generally assumed to be the soft presupposition. For instance, disjunctive closure applied to the alternatives in (11b) gives rise to the entailment that Bill participated - that is (12a) entails (12b).

$$
\begin{aligned}
& \text { a. } \quad \vee\{\operatorname{won}(b), \operatorname{lost}(b)\}=(\operatorname{won}(b) \vee \operatorname{lost}(b)) \\
& \text { b. } \quad \operatorname{participated}(b)
\end{aligned}
$$

Assuming that they are generated in this way in unembedded cases raises the question of how such presuppositions should project. More specifically, the challenge is how to account for the cases in which soft presuppositions project like hard ones and for the cases in which they do not. In response to this, Abusch (2010) assumes a dynamic framework along the lines of Heim 1983 and formulates her pragmatic principle in such a way as to make reference to the local contexts created by the context change potentials of the dynamic meanings that make up the sentences. I 
refer the reader to Abusch's (2010) paper for the details; what is relevant for us is that this strategy effectively mimics the projection behavior of semantic presuppositions, by applying her pragmatic principle globally, in a way that makes reference to the local context of the trigger. Notice that this aspect of the theory is at odds with standard assumptions about the semantics-pragmatics interface, whereby pragmatics only has access to an output of the semantics, generally thought to be a proposition (or a set of propositions). Here instead we would need pragmatics to access the history of the semantic composition in terms of the context change potentials. ${ }^{8}$

More importantly, beyond this conceptual point, there are two empirical problems connected to the way soft presuppositions project in Abusch's (2010) system. First, as seen above, soft and hard presuppositions pattern differently in quantificational sentences. In her system, the projection behavior of soft presuppositions exploits indirectly that of hard presuppositions, so no difference between them is expected with respect to projection. Second, a further problem for this account was pointed out by Sauerland (2008), who observed that when a soft trigger is embedded under another, the disjunctive closure of the combination of alternatives gives rise to an inference that is too weak. As he discusses, a sentence like (13a), which contains the soft triggers win and stop, has intuitively the inference in (13b). However, the disjunctive closure of the alternatives in (13c) only gives rise to $(13 \mathrm{~d}) .{ }^{9,}, 10$

$$
\begin{aligned}
& \text { a. John stopped winning } \\
& \text { b. John used to win } \\
& \text { c. } \mathscr{A} l t=\left\{\begin{array}{l}
\operatorname{stop}(\boldsymbol{w i n}(j)), \operatorname{stop}(\operatorname{lose}(j)) \\
\operatorname{continue}(\boldsymbol{w i n}(j)), \operatorname{continue}(\operatorname{lose}(j))
\end{array}\right\} \\
& \text { d. John used to participate }
\end{aligned}
$$

8 Abusch (2002) acknowledges this issue: "The pragmatic generalization [...] refers to an embedded information state $d$. If we just have the semantic value of the sentence (a certain dynamic proposition or file change potential), it is not possible to apply the condition, because to apply it, one has to find the $d$ which corresponds to the global $c$. To apply the condition, one has to have access to something like a structured proposition (Lewis 1972) which stores the pieces from which the semantic value is composed."

9 Abusch (2010) does not include anymore stop in the list of triggers that she discusses, contrary to Abusch (2002). There are two observations in this respect: the problem is general and it will present itself in any case of a soft trigger embedded into another. Furthermore, if her theory is not meant to apply to aspectuals or factives anymore, she only accounts for a subset of soft triggers.

10 Notice that in this case the inference in (13b) is an entailment of (13a), therefore Abusch (2010) could appeal to this entailment to account for the intuition that (13a) leads to the inference in (13b). However, this would not help her in the case of (ia), which does not entail (ib), but still has (ib) as an inference.

(i) a. John didn't stop winning

b. John used to win 
The presuppositions of soft triggers are obligatory scalar implicatures

Summing up, I believe Abusch's (2010) alternative-based account constitutes an important step towards our understanding of how soft triggers ought to be analyzed. However, some drawbacks to her analysis include the fact that she introduces an ad hoc pragmatic principle of disjunctive closure and assumes a rich representational output of semantics visible to pragmatics in order to account for the projection facts. More importantly, she fails to predict any differences between the projection behavior of soft and hard presuppositions in quantificational sentences, thereby not accounting for half of the difference problem outlined above. Finally, her system makes too weak predictions in the case of a soft trigger embedded into another. Chemla (2009a) proposes to look at presuppositions as a scalar phenomenon and shows that doing so we can account for the projection facts without having to postulate any of the extra assumptions in Abusch 2010. I turn to sketch his idea in the next subsection.

\subsection{Chemla (2009a): the projection of presuppositions as a scalar phenomenon}

The proposal in Chemla 2009a is based on the idea that presuppositional triggers are just like strong scalar items (e.g., every). Namely, in his approach, an expression $\phi$ that intuitively presupposes $p$ and has a weaker alternative, namely $p$ itself. For instance, (14b) is both an entailment and an alternative of (14a).

$$
\begin{aligned}
& \text { a. Bill won. } \\
& \text { b. Bill participated. } \\
& \text { c. } \mathscr{A} l t=\{\operatorname{won}(b), \operatorname{participated}(b)\}
\end{aligned}
$$

As Chemla shows, the proposal predicts the apparent projection behavior through negation, since the negation of (14a), in (15a), has the alternatives in (15c). Given that negation inverts entailment relations, the alternative Bill didn't participate is stronger than the assertion (i.e., Bill didn't win). Assuming a standard theory of scalar implicatures, we obtain the negation of Bill didn't participate (i.e., Bill participated) as an inference of (15a). In other words, we obtain (15b) as a scalar implicature of (15a).

$$
\begin{aligned}
& \text { a. Bill didn't win. } \\
& \text { b. Bill participated. } \\
& \text { c. } \mathscr{A} l t=\{\neg \text { won }(b), \neg \text { participated }(b)\}
\end{aligned}
$$

Beyond negation, the proposal makes fine-grained predictions in the case of quantificational sentences, in line with the results in Chemla 2009a,b. I come back to these predictions and a detailed comparison with the present approach in section 4 below. Before that, I now outline the account that I propose in this paper. 


\section{A scalar implicature-based theory of soft presuppositions}

\subsection{The alternatives of soft triggers}

Following Chemla (2009a), I assume that soft triggers are strong scalar items: they are associated with a set of lexical alternatives, of which they are the strongest elements. For instance, soft triggers like win, know and stop are associated with lexical alternatives as in (16b), (17b) and (18b).

$$
\begin{array}{ll}
\text { a. } & {[[\operatorname{win}]]=\lambda x[\mathbf{w i n}(x)]} \\
\text { b. } & \mathscr{A} l t(16 \mathrm{a})=\{\lambda x[\operatorname{win}(x)], \lambda x[\operatorname{participate}(x)]\} \\
\text { a. } & {[[\mathrm{know}]]=\lambda p \lambda x\left[\mathbf{k n o w}_{x}(p)\right]} \\
\text { b. } & \mathscr{A} l t(17 \mathrm{a})=\left\{\lambda p \lambda x\left[\mathbf{k n o w}_{x}(p)\right], \lambda p \lambda x[p]\right\} \\
\text { a. } & {[[\operatorname{stop}]]=\lambda P \lambda x[\operatorname{stop}(x, P)]} \\
\text { b. } & \mathscr{A} l t(18 \mathrm{a})=\{\lambda P \lambda x[\operatorname{stop}(x, P)], \lambda P \lambda x[\mathbf{u s e d - t o}(x, P)]\}
\end{array}
$$

These alternatives 'grow' via pointwise composition into sentential alternatives. For instance, in (19a), the alternatives are the ones in (19b) and similarly for (20a) and (20b) and (21a) and (21b). ${ }^{11}$

$$
\begin{array}{ll}
\text { a. } & \text { John won. } \\
\text { b. } & \{\operatorname{won}(j), \text { participated }(j)\} \\
\text { a. } & \text { John doesn't know that it is raining } \\
\text { b. } & \left\{\neg \text { know }_{j, w}(p), \neg p(w)\right\} \\
\text { a. } & \text { Mary didn't stop smoking. } \\
\text { b. } & \{\neg \text { stop }(m, \text { smoke }), \neg \text { used-to }(m, \text { smoke })\}
\end{array}
$$

Finally, there appears to be a difference between the alternatives of strong scalar items like every and soft triggers like win which is worth emphasizing: while the alternatives of strong scalar items appears to be symmetric, in that, for instance, some is an alternative of every and every is an alternative of some, the ones of soft triggers do not. In other words, I am assuming that win has participate as an alternative but not that participate has win as an alternative. This in turn predicts that we should not expect participate to behave like a weak scalar item. We can test this prediction by

11 The question at this point is of course where these alternatives come from. Notice that this is the triggering problem (i.e., where presuppositions come from) in a different guise. This is because theories of presuppositions that are based on alternatives do not automatically solve the triggering problem, but rather reframe it so as to question the origin of the alternatives instead: where the alternatives come from and why those alternatives and not others (see Schlenker 2010 for discussion). In this paper, I will not try to answer this questionl; see Romoli $(2011,2012)$ for an attempt to connect this to Abrusán's (2011b) approach to the triggering problem. 
The presuppositions of soft triggers are obligatory scalar implicatures

looking at win and participate in disjunctions, by exploiting the felicity condition, sometimes called "Hurford's Constraint," which bans disjunctions in which one of the disjuncts entails the other (Hurford 1974; see also Singh 2008b). This condition can help us explaining the infelicity of (22).

\#John is in Italy or in Milan.

In cases in which this constraint appears to be violated, like in (23a), Chierchia et al. (in press) argue that there is an embedded scalar implicature in one of the disjuncts, so that there is actually no entailment relation between the disjuncts. In other words, (23a) should be interpreted as (23b).

a. Either John didn't do all of the readings or he didn't do any of them.

b. Either John did some but not all of the readings or he didn't do any of them.

Chierchia et al. (in press) use Hurford's constraint as a diagnostic for scalar implicatures. We can use it here to explore soft presuppositions. In particular, the present proposal expects soft triggers like win to behave like a strong scalar term like all. As (24a) shows this prediction is borne out: in the same way as in (23a) the second disjunct would entail the first, unless we analyze it using local exhaustification as in (24b), with no entailment relation between the disjuncts.

a. Either John didn't win or he didn't participate.

b. Either John participated and didn't win or he didn't participate.

On the other hand, given that we are not assuming that participate has any alternative, we do not expect expressions like participate to behave like (weak) scalar terms. This prediction again is borne out. To see this, consider (25a) and (26): in both cases the second disjunct entails the first, however if we analyze (25a) as (25b), there is no entailment relation between the disjuncts. On the other hand, given that we are assuming that participate has no alternative, we cannot exhaustify the first disjunct and obtain an inference from it, thus the entailment from the second to the first disjunct cannot be disrupted and the infelicity is expected.

a. Either John did some or all of the readings.

b. Either John did some but not all or all of the readings.

\#John participated or won. 


\subsection{A theory of scalar implicatures}

I adopt, for concreteness, an exhaustification-based theory of scalar implicatures based on exhaustification. ${ }^{12}$ The architecture of this theory is composed of four elements: alternatives, an exhaustification principle operating on alternatives, a parsing principle regulating exhaustification, and a mechanism of contextual modulation which can suspend scalar implicatures.

The alternatives are those sketched in the previous section. Exhaustification is obtained through an exhaustivity operator EXH, the meaning of which is akin to that of only: it applies to a proposition and its associated alternatives and it affirms the proposition while negating a subset of its alternatives. I assume that the "excludable alternatives" are all the ones that can be consistently negated without contradicting the assertion and without affirming any other alternative, as defined in (28). ${ }^{13}$

$$
\begin{aligned}
& \llbracket \operatorname{EXH} \rrbracket(\mathscr{A} l t(p))(p)(w)=p(w) \wedge \forall q \in \mathscr{E} x c l(p, \mathscr{A} l t(p))[\neg q(w)] \\
& \mathscr{E} x c l(p, \mathscr{A} l t(p))=\{q \in \mathscr{A} l t(p): p \nsubseteq q \wedge \neg \exists r[r \in \mathscr{A} l t(p) \wedge \neg q \subseteq r]\}
\end{aligned}
$$

Exhaustification of a sentence with respect its alternatives gives rise to scalar implicatures. ${ }^{14}$ By way of illustration, we can now go back to the case in (29a) repeated from above and see how we can derive the inference in (29b), when (29a) is exhaustified.

$$
\begin{aligned}
& \text { a. Not every student came } \\
& \text { b. Some student came }
\end{aligned}
$$

Notice, first, that (29a) is exhaustified with respect to the alternatives in (30). Notice, also, that the alternative $\neg \mathbf{s o m e}$ (student) (came) is not weaker than the assertion (i.e., $\neg$ every(student)(came)), in fact it is stronger. Exhaustification amounts, therefore, to the negation of $\neg$ some(student)(came), which is the inference in (29b).

$$
\mathscr{A} l t=\{\neg \text { every(student)(came) }, \neg \text { some(student)(came) }\}
$$

12 Groenendijk \& Stokhof 1982, van Rooij \& Schulz 2004, Chierchia et al. in press, Fox 2007 a.o.

13 This is the notion of 'innocent exclusion' by Fox (2007) (see also Sauerland (2004), Gazdar (1979) and Magri 2010). As Fox (2007) discusses, this has to be further defined. This is immaterial for our purposes, therefore I will stick to this simple definition.

14 It has been noted in the scalar implicature literature that the definition of excludable alternatives employed overgenerates in certain cases with multiple scalar items (Fox 2007: fn.35, Magri 2010: pp. 35-36 and Chemla 2010: p.56). The problem arises because differently from the standard definition, the one used above considers non-weaker alternatives rather than strictly stronger ones. Fox (2007: fn.35) proposes a constraint on multiple replacements that blocks the generation of some problematic implicatures. The problem is relevant here because Fox's procedure is incompatible with the way to obtain universal projection under "no" to which I turn below. For lack of space I cannot discuss the issue here, but in Romoli 2012: chapter 6, I show that we can amend Fox's procedure and make it compatible with the present proposal. 
The presuppositions of soft triggers are obligatory scalar implicatures

$$
\begin{aligned}
& [\text { EXH }]](\neg \text { every }(\text { student })(\text { came }))= \\
& \neg \text { every }(\text { student })(\text { came }) \wedge \neg \neg \text { some }(\text { student })(\text { came })= \\
& \neg \text { every }(\text { student })(\text { came }) \wedge \text { some }(\text { student })(\text { came })
\end{aligned}
$$

The distribution of scalar implicatures appears to be sensitive to the polarity of the context in which the scalar term is embedded. In other words, scalar implicatures tend not to arise when the corresponding scalar term is embedded in downward entailing contexts. To illustrate, consider the following minimal pair from Chierchia (in press): while (32a) is easily interpreted with an exclusive reading of disjunction (i.e., everyone likes Mary or Sue but not both), this is not the case for (32b). In other words, (32b) is generally interpreted as not suggesting that if someone likes both Mary and Sue, she won't write to the dean. ${ }^{15}$

a. Everyone either likes Mary or likes Sue and will write to the dean.

b. Everyone who either likes Mary or likes Sue will write to the dean.

In order to account for this pattern, the theory adopted here appeals to a parsing principle of non-weakening: unless forced to by contradictions in the context, exhaustification is only allowed if the resulting meaning is not entailed by the meaning without exhaustification. ${ }^{16}$

Do not weaken!: Do not exhaustify a sentence $S$ if exhaustification leads to meaning that is entailed by $S$ (unless you are forced to).

Finally, we need to account for how contextual information can suspend scalar implicatures. I will come back to this in more detail in section 5.

In sum, I remain neutral on the theory of scalar implicatures to adopt. ${ }^{17}$ However, it needs to have three properties. First, it should allow the embeddability of scalar implicatures. ${ }^{18}$ Second, it should account for the sensitivity of scalar implicatures to polarity. Third, it needs a way to account for the optionality of scalar implicatures. Let us now turn to the first set of predictions with respect to projection.

15 To be sure, we can force the strengthened interpretation of a scalar term in a downward entailing context, the point is that no forcing is needed when scalar terms appears in upward entailing contexts, instead. See Panizza et al. 2009 for discussion and experimental data that show the sensitivity of scalar implicatures to polarity.

16 see Chierchia et al. in press, Fox \& Spector 2009 and Magri 2011 for discussion.

17 I remain neutral, in particular, as to whether exhaustification should be interpreted as being part of the grammar or as a shortcut of a pragmatic derivation (see Chierchia et al. in press for discussion)

18 This can be done either by real local application of exhaustification or through a global mechanism which gives rise to the same effect of having embedded scalar implicatures. 


\subsection{A first set of predictions}

\subsubsection{The basic case and negation}

In a basic case like (34a) exhaustification is vacuous. This is because the alternative, John participated, is entailed and therefore cannot be excluded.

$$
\begin{array}{ll}
\text { a. } & \text { John won. } \\
\text { b. } & \{\operatorname{won}(j), \operatorname{participated}(j)\} \\
\text { c. } & {[[\operatorname{EXH}]][\operatorname{won}(j)]=\operatorname{won}(j)}
\end{array}
$$

In the case of a soft trigger embedded under negation, we predict the apparent projection behavior observed by Chemla (2009a). This is because when negation is applied to the alternatives, the entailment relations are reversed. As a result, exhaustification yields the negation of the negated alternatives. Therefore, in the same way as (34a), (35a) leads to the inference that John participated.

$$
\begin{array}{ll}
\text { a. } & \text { John didn't win. } \\
\text { b. } & \mathscr{A} l t=\{\neg \text { won }(j), \neg \text { participated }(j)\} \\
\text { c. } & {[[\operatorname{EXH}]][\neg \text { won }(j)]=\neg \text { won }(j) \wedge \neg \neg \operatorname{participated}(j)=} \\
& \neg \text { won }(j) \wedge \operatorname{participated}(j)
\end{array}
$$

\subsubsection{Antecendents of Conditionals}

Beyond negation, in Romoli 2011 and Romoli 2012, I discuss other embeddings such as polar questions, disjunctions and conditionals. In this paper, the main focus is on quantificational sentences, so I will just go through the case of conditionals as an example. For simplicity, I adopt a material implication analysis of conditionals which states that a conditional is only false if the antecedent is true and the consequent is false (i.e., $p \rightarrow q$ ). This analysis makes a conditional if $p$ then $q$ truth-conditionally equivalent to the corresponding disjunction not $p$ or $q$. Building on this equivalence, I assume that conditionals have the same alternatives as their corresponding disjunctions. In other words, I assume that (36a) has (37a) as its alternatives, in the same way as (36b) has those in (37b). ${ }^{19}$ Notice that in both cases the intuitive motivation of the alternatives is the same: the speaker would have said something stronger by uttering one of the disjuncts instead of the entire disjunction and she would have said something stronger than the conditional by uttering the consequent or the negation of the antecedent.

$$
\text { a. } \quad p \rightarrow q
$$

19 Notice that (36b) is generally assumed to have also the alternative $\neg p \wedge q$, which I am ignoring here because it is immaterial for our purposes. 
The presuppositions of soft triggers are obligatory scalar implicatures

b. $\neg p \vee q$

a. $\mathscr{A} l t=\{p \rightarrow q, \neg p, q\}$

b. $\mathscr{A} l t=\{\neg p \vee q, \neg p, q\}$

As I show now, this analysis can account for the cases of projection of presuppositions from antecedents of conditionals. Consider the case in (38a): when we combine the alternatives of win and those of the conditional we obtain (38b).

a. If Jane won, she is celebrating right now.

b. $\quad \mathscr{A} l t=\left\{\begin{array}{l}\operatorname{won}(j) \rightarrow \operatorname{cel}(j), \operatorname{par}(j) \rightarrow \operatorname{cel}(j), \\ \neg \operatorname{win}(j), \neg \operatorname{par}(j), \operatorname{cel}(j)\end{array}\right\}$

When we exhaustify (38a) with respect to its alternatives in (38b), we can exclude the non-weaker alternative $\neg \operatorname{par}(j)$. Therefore, for a conditional like (38a), we obtain the projection inference that Jane participated. ${ }^{20}$ Summing up, the proposal advanced here can account for the generation of soft presuppositions and their projection through negation and from the antecedent of conditionals.

\subsubsection{Consequent of conditionals and the proviso problem}

In cases of conditionals like (39a), where a soft trigger is embedded in the consequent rather than in the antecedent, the present proposal predicts nothing other than the conditional entailment in (39b).

a. If John was in good shape, he won.

b. If John was in good shape, he participated.

While (39b) might be what we want to conclude in certain contexts, in others intuitively we would want to derive the stronger non-conditional inference that John participated. This is a well-known phenomenon, also known as the "proviso problem" (Geurts 1999) and there are various accounts in the literature, which derive the non-conditional inference from (or in addition to) the conditional one in (39b). ${ }^{21}$ As Chemla (2010) points out, most of the solutions proposed are based on considerations about the plausibility that the speaker believes only the conditional inference, regardless of how this is derived in the first place (in fact, it would be unnatural to restrict these accounts to conditional presuppositions). So adopting one

20 Recall that we are assuming that all non-weaker alternatives are excluded unless they lead to the inclusion of another alternative. This means that we cannot negate the non-weaker alternative $\operatorname{par}(j) \rightarrow \operatorname{cel}(j)$ because this would lead to the negation of the consequent and thus given the assertion we would be forced to conclude the negation of the antecedent, $\neg \mathbf{w i n}(j)$, which is however among the alternatives.

21 Perez-Carballo 2008, Singh 2008a, Franke 2010, van Rooij 2007 among many others. 
of these solutions, we can also derive non-conditional inferences where needed.

It should be noticed, that in the system proposed here the proviso problem arises only in a subset of the cases in which it arises for more traditional presupposition theories like Heim 1983. For instance, for the negation of (39a) in (40a), we obtain the non-conditional inference directly with exhaustification. To illustrate, consider its alternatives in (40b): the alternative $\neg \operatorname{par}(j)$ is excludable, thus giving rise to the inference that John participated.

a. It's not true that if John was in good shape, he won.

b. $\quad \mathscr{A} l t=\left\{\begin{array}{l}\neg[\operatorname{good}-\operatorname{shape}(j) \rightarrow \operatorname{won}(j)], \neg[\operatorname{good}-\operatorname{shape}(j) \rightarrow \operatorname{par}(j)], \\ \neg \neg \operatorname{good}-\operatorname{shape}(j), \neg \operatorname{par}(j), \neg \operatorname{won}(j)\end{array}\right\}$

This points to an asymmetry in the system between how a case like (39a) and that in (40a) give rise to the non-conditional inference that John participated. While in the latter case it arises as a result of exhaustification, in the former it can only emerge given the mechanism adopted for dealing with the proviso problem. Whether there is a difference between these cases is an empirical question that I leave open here. ${ }^{22,23}$

22 Analogous predictions arise in the case of possibility modals: for (ia) we predict the inference in (ib) and again, we could treat it as another instance of the proviso problem and obtain (ic) (see Singh 2009).

(i) a. It's possible that John won.

b. It's possible that John participated.

c. John participated.

On the other hand, in the same way as for the consequents of conditionals, we do predict the inference in (ic) directly via exhaustification in the case of (ii). The same considerations of the case of conditionals apply here.

(ii) It's impossible that John won.

23 An anonymous reviewer raises two objections here. The first one regards the observation that there is a contrast between cases like (ia) and (ib), in which a soft trigger and a strong scalar term are embedded in the consequent, respectively: the intuition is that while (ia) gives rise to the non-conditional inference that John used to smoke (ib) does not give rise to the corresponding inference that John kicked some of the boys.

a. If it's sunny outside, John stopped smoking.

b. If it's sunny outside, John kicked all of the boys.

One way to think about this contrast is as follows. First, strengthening only applies when the conditional inference is such that its antecedent is contextually 'independent' from the consequent, given some notion of independence (e.g., van Rooij 2007). The intuition about the difference between the two cases is the following: it seems relatively easy to find a context in which (ia) is felicitous, i.e., there is some connection between the antecedent and the consequent, yet the antecedent and consequent of the corresponding conditional presupposition (i.e., if it's sunny outside, John used to 
The presuppositions of soft triggers are obligatory scalar implicatures

\subsubsection{Stacked soft triggers}

We saw above that Abusch (2010) makes too weak predictions in the case of a soft trigger embedded under another. For instance, (41a) and (41b) give rise to the inference in (41c), but her system only predicts the weaker inference in (41d).
a. John stopped winning
b. John didn't stop winning
c. John used to win
d. John used to participate

The present proposal can, instead, account for this case too. The inference from (41a) to (41c) is not a problem given that the latter is an entailment of the former. The inference from (41b) to (41c), on the other hand, can be accounted for by exploiting the embeddability of exhaustification. The idea is that in a sentence like (42) we first exhaustify with respect to the embedded scalar term, winning, and then we exhaustify the matrix one, stop.

$$
\text { EXH[not[stop[EXH[PRO winning]]]] }
$$

The exhaustification of the embedded clause is just vacuous. However, it crucially "eats up" the alternatives of win, so that the matrix exhaustification just operates on the alternatives of stop in (44b).

smoke) are independent, so strengthening can happen. On the other hand, it appears much harder to find a context in which (ib) is felicitous, i.e., there is some connection between the antecedent and the consequent, but there is no connection between the antecedent and the consequent of the conditional inference if it's sunny outside, John kicked some of the boys. This is the reason why, I suggest, strengthening does not happen with (ib) (thanks to Emmanuel Chemla for discussion on this).

The second objection has to do with cases like (ii), from Heim 1983, which are intuitively odd. Their oddness would be an indication that the conditional inference in (iii) is not only entailed but also taken for granted.

(ii) ?If John has children, he loves his twins.

(iii) If John has children, he has twins.

Whatever the explanation of the oddness of (ii), analogous examples with soft triggers like (iv) seem to me to be more felicitous.

(iv) If John participated in the tournament, he won the second match.

At any rate, this issue connects to the question of whether we need a separate mechanism that would transform the inferences predicted in the present proposal into something taken for granted in some cases. See footnote 35 below. 


$$
\begin{array}{ll}
\text { a. } & \operatorname{EXH}(\operatorname{win}(j)) \\
\text { b. } & \mathscr{A} l t=\left\{\begin{array}{l}
\operatorname{win}(j) \\
\operatorname{participate}(j)
\end{array}\right\} \\
\text { a. } & \operatorname{EXH}(\neg \operatorname{stop}(\operatorname{win}(j))) \\
\text { b. } & \mathscr{A} l t=\left\{\begin{array}{l}
\neg \operatorname{stop}(\operatorname{win}(j)) \\
\neg \text { used-to }(\operatorname{win}(j))
\end{array}\right\}
\end{array}
$$

At this point, the matrix exhaustification in (44a) is just like the simple case of negation that we saw above: we obtain the inference that John used to win, by negating the stronger alternative that he didn't used to win. ${ }^{24}$ Notice that both exhaustifications are licensed by the condition of Do not weaken!, as applied globally to the entire sentence. This is because it can be shown that (45) is not entailed by (46a), (46b) or (46c). ${ }^{25}$

$$
\begin{aligned}
& \text { EXH[not[stop[EXH[PRO winning]]]] } \\
& \text { a. } \quad \operatorname{EXH[not[stop[PRO~winning]]~} \\
& \text { b. } \quad \operatorname{not[stop[EXH[PRO~winning]]]~} \\
& \text { c. } \quad \operatorname{not[stop[PRO~winning]]~}
\end{aligned}
$$

Summing up, the account sketched above can account for the apparent projection behavior of soft presuppositions under negation and other embeddings like the antecedents of conditionals. Furthermore, it does not run into a problem in the case of a soft trigger embedded under another. I turn now to quantificational sentences.

24 Abusch (p.c. to Sauerland) suggests a similar solution by proposing that her pragmatic principle of disjunctive closure should apply every time a soft trigger is encountered. This would ensure that there would never be a combination of the alternatives of soft triggers. However, given the assumption that the alternatives of soft triggers grow compositionally, the same problem would arise with other alternative bearers like scalar terms. For instance, in the case of (ia) the predicted inference is only (ib) and not the intuitively correct (ic).

(i) a. (Now that he is retired), John didn't stop meeting all the students

b. John used to meet some of the students

c. John used to meet all of the students

In her system, one would have to add a constraint on alternative construction so that the alternative of soft triggers and the ones of other scalar terms do not mix. In the present account, however, they are allowed and expected to combine and, in fact, this combination is at the basis of the account of some puzzles regarding the interaction between soft triggers embedding other scalar terms (see Romoli 2011, 2012 and Chemla 2010).

25 It is easy to see that (46b) and (46c) do not entail (45) as they do not give rise to any inference. (46a) does not entail it because it only gives rise to the inference that John used to participate. This is because $\neg$ used-to(win) $(j)$ is not excludable, as it's negation, used-to(win) $(j)$, together with the assertion $\neg \mathbf{s t o p}$ (win) $($ win $)(j)$ entails another alternative, $\neg \mathbf{s t o p}(\mathbf{p a r t i c i p a t e})(\mathbf{w i n})(j)$. 
The presuppositions of soft triggers are obligatory scalar implicatures

\section{Novel set of predictions}

\subsection{The Empirical Landscape}

The main result reported in Chemla 2009a,b is that the predictions for quantificational sentences appear to depend on the quantifier involved. In particular, universal inferences are obtained when presuppositional triggers are embedded in the scope of universal or negative quantifier sentences. A further result is that in the case of a trigger appearing in the restrictor no evidence for universal projection is found with any quantifier. The following examples, adapted from Charlow 2009, illustrate and summarize these facts about nuclear scopes and restrictors.

a. Each of these ten students stopped smoking.

b. None of these ten students stopped smoking.

c. $\rightsquigarrow$ Each of these ten student used to smoke.

a. Some/at least $5 /$ less than 5 of these ten students stopped smoking.

b. Of these ten students, none of the ones who stopped smoking ate.

c. $\not \leftrightarrow$ Each of these ten students stopped smoking.

As mentioned above, Charlow (2009) has observed that there appears to be a difference between the triggers that Chemla used (know, stop, and possessives) and strong ones like too, also. ${ }^{26}$ The latter, but not the former, project uniformly across all quantifiers. Some of the examples he uses are the following in (49), which would all have the inference in (49c).

a. Each/None/Some of these students [smokes [Marlboros] $]_{F}$ too] at recess.

b. Of these students, none of the ones who [smokes [Marlboros $]_{F}$ too] at recess are blonde.

c. $\rightsquigarrow$ Each of these students smokes something other than Marlboro.

In sum, the pattern of projection of soft presuppositions in quantificational sentences, which emerges from the results in Chemla 2009b and Charlow's (2009) observation is that: (a) the projection appears to depend on the quantifier involved, (b) the projection depends on whether the trigger is embedded in the scope or in the restrictor of the quantifier, (c) the projection of hard presuppositions, instead, appear to be uniformly universal regardless of the position of the trigger and the quantifier involved. In the following, I will show that the present proposal can account for each of (a),(b), and

26 Chemla (2009b) made use in his experiments of triggers that are generally claimed to be soft: possessives, factives and change of state predicates. Although the status of possessives is actually unclear in this respect; see footnote 3 above. 
(c). Before that, let me sketch Chemla's (2009a) and Chemla's (2010) approaches and their problems.

\subsection{Chemla's 2009a and 2010 approaches and their problems}

One of the main motivation for Chemla's (2009a) scalar approach is that it predicts that in the case of quantificational sentences the projection behavior should depend on the quantifier involved, in line with the results outlined above. However, the proposal as it is does not make the right predictions for presupposition projection from the scope of negative quantifiers. This is because it predicts the existential inference in (50b). However, as said above, the participants of Chemla's (2009b) experiment when presented with a sentence like (50a) and asked whether the universal inference in (50c) followed were largely willing to give an affirmative answer.

a. None of these ten students won the marathon.

b. Some of these ten students participated in the marathon.

c. Each of these ten students participated in the marathon.

More precisely, the inference in $(50 \mathrm{c})$ was accepted more often $(\approx 80 \%)$ than the analogous universal inference with a scalar implicature in $(51 \mathrm{c})$ from $(51 \mathrm{a})(\approx 25 \%)$.

a. None of my professors failed all of their students.

b. Some of my professors failed some of their students.

c. All of my professors failed some of their students.

This result tells us that in the scope of negative quantifiers there is a difference in the degree to which soft triggers and strong scalar terms give rise to universal inferences; a difference that is a challenge for Chemla's (2009a) approach and for any proposal that reduces soft presuppositions to scalar implicatures. ${ }^{27}$

In response to this, Chemla (2010) develops his idea by proposing a unified account of presuppositions and scalar implicatures based on a notion of epistemic similarity between the alternatives. I describe his system in more detail in Appendix $\mathrm{A}$, here what is relevant are the following three problematic predictions.

The first problem, inherited from Chemla 2009a, has to do with the difference between soft and hard presupposition in suspension and projection. The latter in particular, as Charlow (2009) discusses, is problematic for Chemla (2009a, 2010) among many others, as they do not distinguish between triggers in projection. ${ }^{28}$

27 Notice that, importantly, these results leave open whether sentences like (51a) do sometimes give rise to universal inferences like that in (51c). I will come back to this below and argue that (51c) is in fact a possible inference of (51a).

28 In particular, it is problematic for those approaches that can instead account very well for the nonuniversal projection of the cases seen above, as nothing in their theory distinguishes between these 
The presuppositions of soft triggers are obligatory scalar implicatures

The second and third problems regard the way he responds to his challenge about the projection of soft presuppositions in negative quantifiers. He abandons the idea that presuppositional triggers are identical to strong scalar terms by assuming different alternatives. For instance, in his system a trigger like win not only has participate as alternative but also not participate, while every does not have not some. This modification makes it so that he only predicts existential inferences in the case of scalar implicatures and universal inferences for the case of presuppositions. In other words, he does not predict the inference in (51c) for a case like (51a), while he predicts the inference in (50c) from (50a). Notice, however, that while this is correct for the case of presuppositional triggers in the scope of no, this also predicts a universal inference in the case of the restrictor of no, (52), an inference that was not supported by the results in Chemla (2009b). This is the second problem.

None of my students who won celebrated.

Finally, and this is the third problem, I argue that while there is a difference in robustness between the inferences in (51c) and that in (50c), the former does arise in some cases. ${ }^{29}$ An argument for the existence of inferences like (51c) comes from Hurford's constraint (see section 3.1 above). On the basis of such constraint, Chierchia et al. (in press) construct a case for the existence of the inference in (53b) from (53a).

a. All of the students did some of the readings

b. None of the students did all of the readings

The logic of the argument is creating a disjunction in which one of the disjuncts entails the other. More precisely, one of the disjuncts entails the other in all readings of (53a) but the one with the scalar implicature in (53b). The case Chierchia et al. (in press) construct is (54), which is felicitous and complies with Hurford's constraint, only if we interpret (54) as (55).

Either every student solved some of the problems, or Jack solved all of them and all the other students solved only some of them.

cases (Chemla 2010, Fox (2008) and George (2008)). Fox (2012) proposes a new trivalent approach, which can account for the differences between triggers in projection. I discuss his proposal in more detail in Appendix B.

29 Chemla himself, in a different paper (Chemla 2008), discusses the example in (ia) and observes that it could have the inference in (ib).

(i) a. None of these 10 teachers killed all of their students.

b. All of these 10 teachers killed some of their students. 
Either every student solved some but not all of the problems, or Jack solved all of them and all the other students solved only some of them.

We can apply the same logic to the case in (51a) and construct a disjunction that is felicitous under Hurford's constraint only if we assume that the first disjunct has the scalar implicature in (51c). The disjunction in (56) has this property.

Either none of my professors failed all of their students or Gennaro failed none and all of the others failed just some.

While a little involved as a sentence, (56) is felicitous. Compare (56) with the case of (57) in which Hurford's constraint is violated, since the second disjunct entails the first. ${ }^{30}$

\#Either none of my professors failed all of their students or Gennaro failed all but one and all of the others failed just some.

I think there is a contrast between (57) and (56), which thereby supports the existence of the inference in (51c) contra Chemla's (2010) predictions.

\subsection{Deriving Chemla-Charlow's pattern}

I propose to develop Chemla's (2009a) idea differently than Chemla (2010), responding to his challenge about negative quantifiers in a way that allows us to predict the inferences from (50a) to (50c) and from (51a) to (51c). I show that if we look carefully at the alternatives of negative quantifiers, we do actually predict the possibility of universal projection from their scope, both for soft presuppositions and for scalar implicatures. As a further consequence, the alternatives assumed here allow an account of the projection of soft presuppositions within negative quantifiers and in particular of the asymmetry between nuclear scope and restrictor, which is not accounted for by Chemla (2010) and other recent accounts I am aware of.

Notice, first, that the predictions of the present proposal fits naturally with Charlow's (2009) observation. This is because it is a theory of soft presuppositions only, therefore in combination with any theory of hard ones which predicts universal projection, we expect a difference in projection between these two classes of triggers.

Second, the predictions for quantifiers are those already pointed out by Chemla (2009a) and they are in line with his experimental results, apart from negative quantifiers. Here I focus on this latter case. I propose to account for the projection behavior by assuming that the alternatives of no should include not every. Notice that it is generally assumed that the former is an alternative to the latter (e.g., Horn

30 Thanks to an anonymous reviewer for suggesting this comparison here. 
The presuppositions of soft triggers are obligatory scalar implicatures

(1972), Levinson (2000)). As seen above, this enables us to derive (58b) from (58a) as a standard scalar implicature.

\section{a. Not every student came.}

b. Some student came.

Since no has to be an alternative to not every for deriving (58b), it follows from the fact that the alternatives of scalar implicatures are symmetric that not every is also an alternative to no. Moreover, there are various independent arguments for decomposing negative quantifiers as negation plus an indefinite. ${ }^{31}$ If these arguments are correct then, given any standard definition of how alternatives grow and the assumption that every and some are scale-mates, we straightforwardly predict that no (=not some) should have the alternative not every.

Given these new alternatives, we can go back to the case of negative quantifiers and we can now replace no with not every in the alternatives. For instance, now for a sentence like (59), we have the alternatives in (60). ${ }^{32}$

$$
\text { No student won. }
$$

$$
\mathscr{A} l t=\left\{\begin{array}{l}
\neg \exists x[\mathbf{s t}(x) \wedge \operatorname{won}(x)], \neg \exists x[\mathbf{s t}(x) \wedge \operatorname{part}(x)] \\
\neg \forall x[\mathbf{s t}(x) \rightarrow \operatorname{won}(x)], \neg \forall x[\operatorname{st}(x) \rightarrow \operatorname{part}(x)]
\end{array}\right\}
$$

31 see Sauerland 2000, Penka 2007, Iatridou \& Sichel 2008 among many others.

32 Notice that I am assuming that quantifiers are endowed with a presupposition requiring their restrictors to be non-empty. For instance, sentences like (ia) and (ib) presuppose that there is at least one student that won.

(i) a. Every student who won came.

b. Some student who won came.

Given this presupposition, then (ia) entails (ib) and similarly, (iia) entails (iib).

(ii) a. No student who won came.

b. Not every student who won came.

More precisely, (ia) and (iia) strawson-entails (ib) and (iib), respectively, where strawson entailment is defined as in (iii) (von Fintel 1999).

(iii) Strawson Entailment: $\phi$ strawson-entails $\psi$ iff for all $w$ and $C$, such that $[\phi \phi]^{C}$ and $\left.[\psi]\right]^{C}$ are all defined in $w$ if $[[\phi]]^{C, w}$ is true then $\left.[\psi \psi]\right]^{C, w}$ is true

Finally, I am also assuming that the notion of excludable alternatives should also be defined using strawson-entailment as in (iv) (thanks to Nathan Klinedinst (p.c.) and Rick Nouwen (p.c.) for discussion on this point).

$$
\mathscr{E} x c l(p, \mathscr{A} l t(p))=\left\{q \in \mathscr{A} l t(p): p \nsubseteq_{s t r} q \wedge \neg \exists r\left[r \in \mathscr{A} l t(p) \wedge \neg q \subseteq_{s t r} r\right]\right\}
$$


When we exhaustify (59) with respect to (60) $\neg \forall x[\mathbf{s t}(x) \rightarrow \operatorname{part}(x)]$ is excludable, thus we obtain the universal inference that every student participated.

$$
\operatorname{EXH}(\neg \exists x[\operatorname{st}(x) \wedge \operatorname{won}(x)])=\neg \exists x[\operatorname{st}(x) \wedge \operatorname{won}(x)] \wedge \forall x[\operatorname{st}(x) \rightarrow \operatorname{part}(x)]
$$

The prediction for negative existentials like no is a universal projection, in line with the findings in Chemla 2009a,b. Furthermore, as I argued above, despite the fact that the acceptance of the corresponding inference for scalar implicatures was much lower in the results of Chemla (2009b), universal inferences also arise in scalar implicature cases like (62a).

a. None of these ten professors failed all of his students.

b. $\rightsquigarrow$ All of these ten professors failed some of his students.

There remains a question, however, which is how the approach here distinguishes between the robustness of the inference in (62b) from (62a) and the universal inference that every student participated from (59). I will come back to this below. Let me turn now to the case of soft triggers in the restrictors of quantifiers.

As mentioned above, the experimental data in Chemla (2009b) for the cases of the restrictors show a weaker acceptance rate of universal inferences for all quantifiers. The predictions of the present account here are in line with this result as non-universal inferences are predicted for the restrictors of both no and every. While the latter is expected, given the asymmetry between the scope and restrictor of every, the former is the novel and surprising prediction. Let me sketch it in more detail. The prediction for a case like (63a) is only the non-universal inference in (63b).

a. None of the students who won were upset.

b. There is at least a student who participated but didn't win and was upset.

To see this consider the alternatives of (63a) in (64). Notice that crucially the only excludable alternative is $\neg \exists x[(\operatorname{stud}(x) \wedge \operatorname{part}(x)) \wedge \operatorname{upset}(x)] .{ }^{33}$ Hence we derive the non-universal inference in (65): some student who participated was upset. ${ }^{34}$

$33 \overline{\text { The alternative } \neg \forall x[(\operatorname{stud}(x) \wedge \operatorname{part}(x))} \rightarrow \operatorname{upset}(x)]$ is entailed by the assertion, hence it cannot be excluded: if none of the students who won were upset, then it must be the case that not all of the students who participated were upset.

34 This is provably equivalent to (i): there is some student who participated but did not win and was upset.

$$
\neg \exists x[(\operatorname{stud}(x) \wedge \operatorname{won}(x)) \wedge \operatorname{upset}(x)] \wedge \exists x[\operatorname{stud}(x) \wedge \operatorname{part}(x) \wedge \neg \operatorname{win}(x) \wedge \operatorname{upset}(x)]
$$


The presuppositions of soft triggers are obligatory scalar implicatures

$$
\begin{aligned}
& \mathscr{A} l t=\left\{\begin{array}{l}
\neg \exists x[(\operatorname{stud}(x) \wedge \operatorname{won}(x)) \wedge \operatorname{upset}(x)] \\
\neg \exists x[(\operatorname{stud}(x) \wedge \operatorname{part}(x)) \wedge \operatorname{upset}(x)] \\
\neg \forall x[(\operatorname{stud}(x) \wedge \operatorname{won}(x)) \rightarrow \operatorname{upset}(x)] \\
\neg \forall x[(\operatorname{stud}(x) \wedge \operatorname{part}(x)) \rightarrow \operatorname{upset}(x)]
\end{array}\right\} \\
& \operatorname{EXH}(\neg \exists x[(\operatorname{stud}(x) \wedge \operatorname{won}(x)) \wedge \operatorname{upset}(x)])= \\
& \neg \exists x[(\operatorname{stud}(x) \wedge \operatorname{won}(x)) \wedge \operatorname{upset}(x)] \wedge \exists x[\operatorname{stud}(x) \wedge \operatorname{part}(x) \wedge \operatorname{upset}(x)]
\end{aligned}
$$

Summing up, the pattern of projection of soft presuppositions in quantificational sentences, which emerges from the results in Chemla 2009b are: (a) the projection appears to depend on the quantifier involved, (b) the projection depends on whether the trigger is embedded in the scope or in the restrictor of the quantifier. The present theory can derive both of these results. Also, by being restricted to a theory of soft presuppositions, the present proposal is compatible with the differences between soft and hard presuppositions observed by Charlow (2009). I turn now to the difference between soft presuppositions and scalar implicatures.

\section{Soft presuppositions, hard presuppositions and scalar implicatures}

In this section, we focus more on the relationship between soft and hard triggers, on the one hand, and soft triggers and strong scalar terms, on the other. We saw above that the present proposal can account for the differences between the former and the similarities between the latter. In approaches like the one pursued here, however, the challenge becomes explaining also the other side of the coin: namely the similarities between hard and soft triggers and the differences between soft triggers and strong scalar terms. While I won't be able to address all of the issues surrounding these relationships within the limits of the present work, in this section I will show how some of them can be accounted for with relatively simple assumptions.

\subsection{Soft versus Hard Presuppositions}

We saw a above that for our purposes, we do not need to decide on a specific theory of hard presuppositions. It is enough that we assume a theory that predicts universal projection of hard presuppositions in quantificational sentences, in order to account for the projection differences between hard and soft presuppositions. ${ }^{35}$ In the same way, we also predict the difference in terms of suspendability, simply because the mechanisms for suspending hard versus soft presuppositions are different (if hard

35 See Schlenker 2008 for a discussion of different recent theories of presuppositions and their predictions. 


\section{presuppositions can be suspended at all). ${ }^{36}$}

36 There are two further properties generally assumed to be a characteristic of presuppositions connected to their discourse status. The first property regards the fact that presuppositions are generally felt to be taken for granted in the context at the moment of utterance of the presupposing sentence. This is captured in the approach initiated by Stalnaker (1974), by a requirement that presuppositions should be entailed in the context at the moment of utterance of the presupposing sentence. While this may very well be correct for the case of hard presuppositions, it is unclear to me that this should also apply to soft presuppositions. Consider (i): while it is of course felicitous in a context which entails that John participated, we can felicitously utter it also in a context that does not.

(i) John didn't win the race

The response from the Stalnakerian approach is proposing that there is a process of accommodation of presuppositions, which allows us to add the presupposition to the context in which (i) is uttered, if it is not already entailed. However, one could instead defend the view that there is actually no condition that requires soft presupposition to be contextually entailed; rather, it just can happen that they are. If soft presuppositions are inferences, when they happen to be contextually entailed already, no vacuous exhaustification occurs (this could be traced back to the do not weaken condition). On the other hand, if they are not contextually entailed, they arise via exhaustification. Finally, notice that the "hey wait a minute test", generally used as a diagnostic for the discourse status of presuppositions, applies to soft presuppositions, as (ii) shows (von Fintel 2008).

(ii) a. John stopped smoking.

b. Hey wait a minute! I didn't even know that he used to smoke.

However, the hey wait a minute test is problematic as a test for presuppositions. This is because it appears to work also with simple entailments (thanks to Danny Fox (p.c.) for pointing this out to me). Consider (iiia) and (iiib) below, where we are talking about John who is currently on a trip from Rio to New York.

(iii) a. John is in Miami.

b. Hey wait a minute! I didn't even know he left Brazil already .

In sum, if we can use this test with entailments as in (iiib), we cannot rely on this test to decide whether something is a presupposition or not.

The second property regards truth-value judgements. An anonymous reviewer points out in a context in which John didn't kick any of the boys (iva) strikes one as obviously false, while it is not obvious how to judge (ivb) in a context in which John never smoked.

(iv) a. John kicked all of the boys.

b. John stopped smoking.

Our intuitions about falsity and truth-value gaps is a complicated terrain to which I cannot make justice to within the limits of the present paper (von Fintel 2004 and references therein). A strategy of response to the contrast in (iii) in the present account is to postulate an asymmetry in the conditions under which we judge (iva) and (ivb) false, even if the theory predicts both of them to be false. 
The presuppositions of soft triggers are obligatory scalar implicatures

\subsection{Soft presuppositions versus scalar implicatures}

Above we focused on the similarities between soft triggers and strong scalar items, what we have called the similarity problem, and we showed how the present proposal can account for it. We need, however, to also account for the differences between soft presuppositions and scalar implicatures. In particular, we saw that while under negation they behave in the same way, in that they both appear to project systematically, in other embeddings, like the antecedent of conditionals, soft presuppositions typically project out, while it is not clear that scalar implicatures do. For instance, both the inferences from (66a) to (66b) and that from (67a) to (67b) appear robust and systematic. On the other hand, while (68b) is clearly an inference of (68a), unless it is contradicted in the context, it is unclear that (69b) is in the same way an inference of (69a).

$$
\text { a. Mary didn't win. }
$$

b. Mary participated.

a. Mary didn't meet all of the students.

b. Mary met some of the students.

a. If Mary won, she will be very happy.

b. Mary participated.

a. If all of the students came, Jane is happy.

b. Some of the students came.

Another important difference is the projection from the scope of negative quantifiers. While I argued above that (71b) is an inference of (71a), this appears intuitively less robust than the inference from (70a) to (70b), as also experimentally shown by Chemla (2009a,b).

a. No student discovered that he was accepted.

b. Every student was accepted.

a. No student did all of the readings.

b. Every student did some of the readings.

In order to account for the differences above, I propose that while soft triggers are just like strong scalar terms, they differ in that they are insensitive to contextual modulation. More specifically, they give rise to obligatory scalar implicatures, in a sense to be specified below. In the following, I first sketch the notion of obligatory scalar implicatures and how they differ from non-obligatory ones and then I show that this distinction can account for the differences between soft presuppositions and scalar implicatures. 


\subsubsection{Obligatory scalar implicatures and soft presuppositions}

One central characteristic of implicatures is their context dependence or 'optionality'. There are two ways, in particular, in which scalar implicatures are suspended. First, they are suspended when the speaker says explicitly that she is ignorant about the stronger alternative: (72) does not suggest that the speaker thinks that not all of the students came.

(72) I don't know if all of the students came. But some did.

A second contextual modulation is linked to what is relevant, generally modelled as what the (explicit or implicit) question under discussion is. ${ }^{37}$ For instance, when a sentence like (73a) is understood as an answer to a question like (74a) we tend to derive the inference in (73b), but we tend not to do it if it is an answer to (74b).

a. Many students came.

b. Not every student came.

a. How many students came?

b. Did many students come?

Any theory of scalar implicatures needs a mechanism to account for the contextdependence above. Suspension by ignorance can be accounted for straightforwardaly if we assume that scalar implicatures should not lead to contradictions in the context or to imputing irrationality to the speaker. A standard way to account for suspension by relevance is to assuming that the alternatives over which scalar implicatures are computed are only those that constitute an answer to the question under discussion. For instance, while the alternative every student came is an answer to (74a), it is not an answer to (74b), therefore it is only considered in the former case. ${ }^{38}$

Recently, it has been proposed in the literature that some scalar implicatures are not subject to suspension by relevance (Spector 2007, Chierchia in press; see also Magri 2010). In other words, for certain scalar items, the pragmatic mechanism of relevance is allowed to kick in and carve out the set of alternatives depending on the question under discussion. For others, on the other hand, relevance is not taken into account and exhaustification has to always happen on the entire set of alternatives. Building on this idea, I propose that soft presuppositions are scalar implicatures of this latter kind and that this accounts for the differences between them and regular scalar implicatures with respect to their projection behaviour in connectives and

37 See van Rooij (2002), Fox \& Katzir (2011), Zondervan (2009), Magri (2010) among many others.

38 I will not formalize precisely what counts as an answer to a question here. See Romoli 2012: chapter 1 for an implementation based on Heim 2011. 
The presuppositions of soft triggers are obligatory scalar implicatures

quantificational sentences. ${ }^{39}$

If the idea is that relevance plays no role in the case of soft triggers and exhaustification is obligatory and always on the full set of alternatives, how do we account for the suspension of soft presuppositions in cases like (75)?

(75) I don't know whether Mary ended up participating, but if she won, she must be celebrating.

I propose that suspension of soft presuppositions come about through the scope of exhaustification. This is possible because in the case of strong scalar items local exhaustification is always vacuous. For instance, in (75), we know that win comes with a requirement that exhaustification always has to happen. There are, however, two sites at which this can happen: globally as in (76a) or embedded in the antecedent, as in (76b).

a. $\mathrm{EXH}[\mathrm{if}$ she won she is celebrating]

b. if [EXH[she won]] [she is celebrating]

(76a) gives rise to the soft presupposition that Mary participated in the way proposed above. (76b), on the other hand, does not, since the exhaustification of the embedded complement is vacuous. ${ }^{40}$ Furthermore, given that the only way to suspend the presupposition is via local exhaustification and given that this violates the do not weaken! requirement, it will only be possible when there is explicit information in the context in contradiction with what global exhaustification would yield. This prediction is borne out: a soft presupposition projects unless we have information in the context that the speaker is ignorant about it. What happens in the case of scalar

39 Simons et al. (2010) propose a theory of the projection of presuppositions (and other inferences) which is also connected to the notion of questions under discussions. Roughly, they propose that presuppositions project when they are not at issue relative to the question under discussion. I leave the comparison between the present account and theirs for further research. Let me just point to a discussion by Abrusán 2011a: pp.500-501 on some problematic predictions for the idea that relevance affects the projection of presuppositions. For instance, she discusses the case of (i), where the presupposition that John used to smoke is relevant information (it is an answer to the question), therefore it is predicted not to project, contrary to intuitions.

(i) a. What do you know about John?

b. He still didn't quit smoking.

40 To see this notice that exhaustification at that scope site is like exhaustifying the unembedded sentence in (ia), with respect to the alternatives in (ib).

(i) a. Mary won.

b. $\quad$ Mary won, Mary participated 
implicatures instead? Here we have more options for suspensions, as we also have the modulation of the alternatives given the question under discussion. Consider what happens when a scalar term is embedded in the antecedent of a conditional like (77a). The question here is whether we predict the inference in (77b).

a. If John did all of the readings, he will go out tonight.

b. John did some of the readings.

A natural question under discussion for (76a) is (78) (von Fintel 1995). As is easy to see, the alternative (79) that would give rise to the inference in (77b) is not an answer to (78) and is therefore not relevant.

(78) What will John do if he did all of the readings?

(79) $\neg$ [John did some of the readings]

In sum, in the case of a scalar term embedded in the antecedents of conditionals like (77a), given a reasonable question under discussion, the alternatives that would give rise to the inference in (77b) are not going to be relevant. This, I argue, is the source of the difference between the scalar implicatures and the soft presuppositions cases.

Finally, the approach discussed here also predicts a difference in robustness between (80b) and (81b).

a. No student won.

b. Every student participated.

a. No student did all of the readings.

b. Every student did some of the readings.

Given that I assuming that the exhaustification of a soft trigger like win is obligatory, while that of a strong scalar items like all is subject to relevance, this means that the inference from (80a) to (80b) can only be cancelled with local exhaustification, as in (82). As we know from above, this is a dispreferred option so it is going to be chosen only if information in the context contradicts the universal inference we would obtain with global exhaustification. An example of this case is in (83).

(83) I don't know whether each of the students participated, but none of them won.

On the other hand, since the exhaustification of strong scalar term is optional, the inference from (81a) to (81b) can be suspended by relevance and as this option does not violate do not weaken!, it can be done without any special information in the 
The presuppositions of soft triggers are obligatory scalar implicatures

context contradicting the universal inference. ${ }^{41}$

\subsection{A note on Local accommodation and local exhaustification}

Before concluding, there is one point that I would like to emphasise about suspension of soft presuppositions and local exhaustification. ${ }^{42}$ It is well known that suspension of presuppositions is marked. For instance, the most natural reading of (84a) is one in which we infer (84b). We can suspend (84b), but we need to force it. For instance with a continuation like (85) and stress on the auxiliary. ${ }^{43}$

a. Bill didn't win the race.

b. Bill participated in the race.

c. Bill didn't win the race, because he didn't even participate!

To account for this pattern, all theories of presupposition suspension that I am aware of make use of an ad-hoc mechanism designed precisely for the task (e.g., local accommodation in Heim (1983), the floating-A operator in Beaver \& Krahmer 2001) and stipulate that the local application of this mechanism is disprefered. In the present approach, instead, the account of suspension comes about through something that has been argued for independently, namely, local exhaustification. This allows us to reduce the stipulated 'preference' for global accommodation to the preference of exhaustification possibilities. In particular, we can appeal to the Do not weaken! parsing principle above so that the question of whether soft presuppositions are suspended in a given context reduces to the question of how people parse the sentence, given available exhaustification possibilities.

41 More specifically, the prediction is that the inference in (ib) from (ia) will only arise in the case of a question like (ii) but not for (iiia) and (iiib).

(i) a. None of the students did all of the readings.

b. All of the students did some of the readings.

(ii) How many students did how many readings?

(iii) a. How many students did all of the readings?

b. How many readings did none of the students do?

The judgements are subtle and arguably require experimental investigation, which I leave for further research. What is important at this point is that there are more suspension options for the inference in (80b) than that in (81b) and this, I argue, is the source of the difference in robustness that emerged in Chemla's (2009b) results.

42 Thanks to an anonymous reviewer for suggesting to highlight this point and for relevant discussion.

43 The markedness of the reading without the presupposition has also recently been show experimentally by Chemla \& Bott (2013), who found a processing cost associated to the reading without the presupposition versus that with it. 


\section{Conclusion}

In this paper, building on Chemla 2009a and Abusch 2010, I developed a scalar implicature-based theory of soft presuppositions. I showed that it can explain how soft presuppositions can be suspended, while also accounting for their 'projection' behavior when they are not. The two main contributions of the proposal are: (a) an account of the projection behavior of soft presuppositions both from the scope and the restrictors of quantificational sentences, in line with the experimental results reported in Chemla 2009a,b, (b) an account based on the notion of obligatoriness of scalar implicatures of how soft presuppositions are different from hard presuppositions on the one hand and similar to scalar implicatures on the other. I also began to address the other side of the coin, namely the similarities between soft and hard presuppositions, on the one hand, and the differences between soft presuppositions and scalar implicatures, on the other. Finally, I have shown that the present proposal also reduces the pattern of soft presupposition suspension to independent principles needed in the theory of scalar implicatures. 
The presuppositions of soft triggers are obligatory scalar implicatures

\section{Appendix A: comparison with Chemla in preparation}

Chemla (2010) proposes a unified alternative-based approach to presuppositions, free choice inferences and scalar implicatures. The architecture is similar to Abusch's (2010) proposal: a global pragmatic principle operates on a set of alternatives and gives rise to various inferences. In the following I briefly summarize his proposal and highlight the differences with respect to the theory proposed in this paper.

\subsection{A sketch of the theory}

Chemla's (2010) has two main components: first, a method of constructing alternatives from a sentence (i.e. a set of replacements), which also provides a way of grouping them into separate subsets of alternatives. Second, a pragmatic principle that requires that a speaker is in the same epistemic status with respect to the alternative in each subset. Let us go through both components in more detail.

The method of constructing alternatives is based on the standard assumption that scalar items are associated to sets of lexical alternatives. In the case of scalar implicatures, Chemla (2010) assumes that a scalar item like many has the standard lexical alternatives some and every. A first novel aspect is that he also assumes that there are two additional scale mates, which are a strong contradictory alternative $\perp$ and a weak tautological one T. ${ }^{44}$ Furthermore, Chemla (2010) assumes that there are three procedures for constructing alternatives, what he calls "transformations": (a) "stronger replacements", which substitute each scalar term with a stronger scalemate, (b) "weaker replacements", which do the same but with weaker scale-mates and (c) "connective split", which for any sentence $p \otimes q$, where $\otimes$ is any connective, it substitutes $p \otimes q$ with $p$ and $p \otimes q$ with $q$. In the case of a sentence like (85a), schematized in (85b), we, hence, obtain the alternatives in (86) through stronger and weaker replacements.

$$
\begin{aligned}
& \text { a. Many students came. } \\
& \text { b. MANY } \\
& \left\{\begin{array}{l}
\top \\
\text { SOME } \\
\text { EVERY } \\
\perp
\end{array}\right\}
\end{aligned}
$$

The second novel aspect of the proposal is that sets of alternatives like the one in (86) are then divided into subsets of alternatives, according to how they are constructed

44 More precisely he assumes that there are scale-mates that create a tautological or contradictory meaning at the first scope site. 
(stronger replacements, weaker replacements, or connective split). The alternatives in each subset are called "similar" alternatives. In the case of (86) the subsets of similar alternatives are in (87a) and (87b).

$$
\begin{array}{ll}
\text { a. } & \{\text { SOME }, \top\} \\
\text { b. } & \{\text { EVERY }, \perp\}
\end{array}
$$

weaker replacements

stronger replacements

In the case of a connective like disjunction in (88), the set of similar alternatives are in $(89 a)-(89 c) .{ }^{45}$

$$
\begin{aligned}
& p \vee q \\
& \text { a. }\{p, q\} \\
& \text { b. }\{(p \wedge q), \perp\} \\
& \text { c. } \quad\{\top\}
\end{aligned}
$$

$$
\begin{array}{r}
\text { connective split } \\
\text { stronger replacements } \\
\text { weaker replacements }
\end{array}
$$

Given the alternatives, constructed and divided in the way above, there is a second component of the theory, which is a pragmatic felicity condition operating on these alternatives. The felicity condition that Chemla (2010) proposes is in (90) and the notion of epistemic similarity is defined in (91).

(90) Similarity Principle: An utterance is felicitous only if its similar alternatives are epistemically similar.

(91) Epistemic Similarity (weak) Two propositions $\phi$ and $\psi$ are epistemically similar if $B_{S}[\phi] \leftrightarrow B_{S}[\psi]$ (where $B_{S}[\phi]$ indicates that the speaker believes that $\phi$ )

The similarity principle requires that similar alternative, that is those alternatives that are grouped together by the same transformation, have to be either believed to be true together or believed to be false together by the speaker. For instance in the case of (85a), the inferences that we obtain given (90) are (92) and (93).

$$
\begin{aligned}
& B_{S}[\mathrm{SOME}] \leftrightarrow B_{S}[\top] \\
& B_{S}[\mathrm{EVERY}] \leftrightarrow B_{S}[\perp]
\end{aligned}
$$

What (92) requires is that the speaker believes that some of the students came if and only if she believes the tautological proposition, in other words it requires that the speaker believes that some of the students came. This is already entailed by the assertion. (93), instead, requires that the speaker believes that every student came if and only if she believes the contradictory proposition. This, in turn, means that it's false that the speaker believes that every student came. We hence obtain the 
The presuppositions of soft triggers are obligatory scalar implicatures

inference in (94) for a sentence like (85a).

$$
\neg B_{S} \text { [every student came] }
$$

The type of inferences in (94) are what Chemla (2010) calls "weak epistemic similarity inferences". These inferences can then be strengthened given the assumption that the speaker is opinionated with respect to the alternatives: for any alternative $\phi,\left(B_{S}[\phi] \vee B_{S}[\neg \phi]\right)$ as long as the resulting inference is consistent with all the weak inferences. ${ }^{46}$ So now when possible a weak similarity inference $\left(B_{S}[\phi] \leftrightarrow B_{S}[\psi]\right)$ will be strengthened to a strong similarity inference $B_{S}[\phi \leftrightarrow \psi]$. In the case of (85a) we can strengthen (93) to (95).

$$
\begin{aligned}
& B_{S}[\text { EVERY } \leftrightarrow \perp]= \\
& B_{S}[\neg[\text { every student came }]]
\end{aligned}
$$

Turning now to the case of presuppositions, Chemla (2010) assumes that any $\phi$ generally assumed to be a presuppositional trigger with presupposition $p$ is instead a non-presuppositional scalar item associated to the alternatives $p$ and $\neg p$. In addition, the weak tautological alternative $T$ and the strong contradictory one $\perp$ are again assumed to be scale-mates. In the same way as above, the alternatives of a sentence like (96) are constructed and divided into two groups of similar alternatives, as in (97a) and (97b).

$$
\begin{aligned}
& \text { a. John knows that it's raining. } \\
& \text { b. KNOW }{ }_{j} \text { (RAIN) }
\end{aligned}
$$

$$
\text { a. }\{\text { RAIN }, \top\}
$$$$
\text { b. }\{\neg \text { RAIN }, \perp\}
$$

As in the case of scalar implicatures, the similarity principle requires that similar alternatives are either believed to be true together or believed to be false together by the speaker. in the case of (96a), we obtain the weak epistemic similarity inferences in (98a) and (98b), which can be strengthened to (99a) and (99b).

$$
\begin{array}{ll}
\text { a. } & B_{s}[\mathrm{RAIN}] \leftrightarrow B_{s}[\top] \\
\text { b. } & B_{s}[\neg \mathrm{RAIN}] \leftrightarrow B_{S}[\perp] \\
\text { a. } & B_{s}[\mathrm{RAIN} \leftrightarrow \top] \\
\text { b. } & B_{s}[\neg \mathrm{RAIN} \leftrightarrow \perp]
\end{array}
$$

Both (99a) and (99b) say that the speaker believes that it's raining. So we obtain the presupposition of a sentence like (96a)

46 See Sauerland (2004) for an analogous strengthening process that he calls "the epistemic step". 
In essence, the proposal in Chemla 2010 provides a set of procedures for constructing alternatives and dividing them into subsets of similar alternatives. Furthermore, it comes with a pragmatic principle that requires that the speaker be in the same epistemic status with respect to the alternatives obtained through the same procedure. This principle gives rise to presuppositional inferences, which can in certain cases be strengthened. Let us turn now to a comparison between this system and the present proposal.

\subsection{Comparison}

Given that Chemla 2010 is a unified account of presuppositions, scalar implicatures, and free choice inferences, a complete comparison should eventually be done in each of these areas. More specifically, one should compare the present account of soft presuppositions together with the exhaustivity-based account of scalar implicatures and free choice inferences that I adopt on one hand and the proposal by Chemla (2010) on the other. Here I restrict the comparison to the presupposition part and emphasize three main differences between Chemla (2010)'s and the present proposal.

The first aspect regards how he responds to his own challenge about negative quantifiers discussed above in section 4. Recall that Chemla (2009a) claims that the scalar approach to presuppositions does not make the right predictions for presupposition projection from the scope of negative quantifiers. This is because it would predict the existential inference in (100b), while the participants of Chemla's (2009b) experiment reported the strong universal inference in (100c) for sentences like the one in (100a).
a. No student won.
b. Some student participated.
c. Every student participated.

More precisely, the inference in (100c) from (100a) was accepted more often than the analogous inference with a scalar implicature in (101c) from (101a).
a. No student did all of the readings.
b. Some student did all of the readings.
c. Every student did some of the readings.

I showed in section 4 that by assuming independently motivated alternatives for negative quantifiers we can in fact account for the universal inference in (101b) and furthermore, assuming a difference in terms of whether they are subject to relevance or not, we can also account for the difference between scalar implicatures and soft presuppositions. Chemla (2010), instead, responds to the challenge above 
The presuppositions of soft triggers are obligatory scalar implicatures

by effectively abandoning the idea that presuppositional triggers are identical to strong scalar items, and assuming different alternatives for scalar implicatures and presuppositions. As discussed, he assumes that presuppositional triggers have both a weaker alternative and it's negation. In other words, a presupposition trigger $\phi$ has both the weaker $p$ and its negation $\neg p$ as scale mates. On the other hand, strong scalar terms like every do not: every does not have $\neg$ some in addition to some as a scale-mate. This difference is crucial in order to account for the difference between the projection from the scope of negative quantifiers, because he only predicts existential inferences in the case of scalar implicatures, while universal inferences for the case of presuppositions. To see this considers a sketch of the derivation for the case of (102a), with the set of similar alternatives in (102b) and (102c).

$$
\begin{aligned}
& \text { a. } \quad \text { No one won. } \\
& \text { b. }\{\text { NO x, participated(x), NO x, } \top\} \\
& \text { c. }\{\text { NO x, } \neg \operatorname{participated}(x), N O x, \perp\}
\end{aligned}
$$

The result of applying the epistemic similarity principle to the set in (102b) is the existential inference in (103): the speaker doesn't believe that no one participated, which can then be strengthened to the speaker believes that someone participated.

$$
\begin{aligned}
& B_{s}[\operatorname{NO} x, \operatorname{PARTICIPATED}(x) \leftrightarrow \text { NO } x, \top]= \\
& B_{s}[\operatorname{NO} x, \operatorname{PARTICIPATED}(x) \leftrightarrow \perp]= \\
& \neg B_{s}[\operatorname{NO} x, \operatorname{PARTICIPATED}(x)]==^{47} \\
& B_{s} \neg[\operatorname{NO} x, \operatorname{PARTICIPATED}(x)]= \\
& B_{s}[\exists x, \operatorname{PARTICIPATED}(x)]
\end{aligned}
$$

The result of applying it to (103c) is, instead, is the universal inference in (104): the speaker believes that everyone participated.

$$
\begin{aligned}
& B_{s}[\text { NO } x, \neg \operatorname{PARTICIPATED}(x) \leftrightarrow \text { NO } x, \perp]= \\
& B_{S}[\operatorname{NO} x, \neg \operatorname{PARTICIPATED}(x) \leftrightarrow \top]= \\
& B_{S}[\operatorname{NO} x, \neg \operatorname{PARTICIPATED}(x)]= \\
& B_{S}[\forall x, \operatorname{PARTICIPATED}(x)]
\end{aligned}
$$

Notice that the universal inference crucially comes from the set of similar alternatives that contains the negated alternative, which Chemla (2010) only assumes for presuppositions. In the case of every we do not have such alternative (i.e., we do not have $\neg$ some), hence we can only obtain the existential inference. To see this consider (105a) with the only possible set of similar alternatives in (105b).

a. No student did all of the readings.

47 Assuming that the speaker is 'competent,' in the sense of Sauerland (2004). 


\section{b. $\quad\{$ NO x, SOME, NO x, $\top\}$}

From (105b) we can only obtain the existential inference that the speaker doesn't believes that no student did some of the readings as shown in (106).

$$
\begin{aligned}
& B_{S}[\text { NO } x, \text { SOME } \leftrightarrow \text { NO } x, \top]= \\
& B_{s}[\text { NO } x, \text { SOME } \leftrightarrow \perp]= \\
& \neg B_{s}[\text { NO } x, \text { SOME }]= \\
& B_{S} \neg[\text { NO } x, \text { SOME }]= \\
& B_{S}[\exists x, \text { SOME }]
\end{aligned}
$$

In sum, by assuming different alternatives for presuppositions and strong scalar items Chemla (2010) can account for the difference between scalar implicatures and presuppositions in the acceptance of the universal projection inference in the case of the scope of negative quantifiers. I can see two problems in connection with this: first, contrary to the present proposal, Chemla's (2010) system can never predict a universal inference for the case of scalar implicatures. I argued above, however, that a sentence like (107a) has (107b) as an inference.

a. None of these teachers killed all of their students.

b. All of these teachers killed some of their students.

Furthermore, it is unclear why, given the motivations in section 4 above we should not also have not every as a scale mate of no. Recall from section 4.3 above, that a sentence with not every like (108a) must have the alternative with no in (108b) in order to account for the inference from (108a) to (108c).
a. Not every student came.
b. No student came.
c. Some student came.

Furthermore, if we accept the arguments for the decomposition of no into negation plus indefinite (cf. section 4), not some, it is unclear how to block the transformation of sentences containing no (=not some) so that it does not create sentential alternatives with not every (substituting every for some in the scope of negation). We could of course add to Chemla's (2010) system the assumption that not every is in fact a scale mate of no and we would obtain the universal inference in (107b). To see this consider the set of alternatives in (109b) that we would obtain by further replacing NO in the set in (109a) with NOT EVERY.

$$
\begin{array}{ll}
\text { a. } & \{\text { NO x, SOME, NO x, } \top \text { }\} \\
\text { b. } & \{\text { NOT EVERY X, SOME, NOT EVERY } x, \top\}
\end{array}
$$


The presuppositions of soft triggers are obligatory scalar implicatures

Applying the epistemic similarity principle to (109b) we obtain (110): the speaker believes that everyone did some of the readings.

$$
\begin{aligned}
& B_{S}[\text { NOT EVERY } x, \text { SOME }] \leftrightarrow B_{S}[\text { NOT EVERY } x, \top]= \\
& B_{S}[\text { NOT EVERY } x, \text { SOME }] \leftrightarrow B_{S}[\perp]=\neg B_{S}[\text { NOT EVERY } x, \text { SOME }]= \\
& B_{S} \neg[\text { NOT EVERY } x, \text { SOME }]=B_{S}[\text { EVERY } x, \text { SOME }]
\end{aligned}
$$

We can, therefore, amend Chemla's (2010) system so as to obtain the inference in (107b), however the account that he offers for the difference between between presuppositions and scalar implicatures in the robustness of acceptance of the universal inference would be lost. The fact that the present proposal can account both for the possibility of the inference in (107b) and the difference between scalar implicatures and presuppositions is an argument in its favor.

A second difference regards the fact that the present proposal predicts an asymmetry between nuclear scope and restrictor of negative quantifiers in that soft presuppositions project universally from the former but not from the latter. In other words, the inference in (111c) is predicted from (111a) but not from (111b).
a. No student won.
b. No student who won celebrated.
c. Every student participated.

This prediction appears intuitively correct. Furthermore, Chemla (2009b) also tested cases like (111b) in his experiments and while the results are less clear than in cases like (111a), they suggest that (111c) is accepted much less from (111b) than from (111a). This difference is, however, not accounted for by Chemla (2010) given the symmetry between the scope and restrictor of negative quantifiers, he makes the same universal prediction for both of them (thanks to Emmanuel Chemla for discussion on this point).

The third aspect that distinguishes the present proposal from Chemla's (2010) account is that the former is explicitly restricted to soft presuppositions and this can account for the context dependence of the former versus the latter and their difference in the case of quantificational sentences. ${ }^{48}$

Summing up, I followed the main idea in Chemla 2009a, but proposed to develop it differently from the alternative route explored in Chemla 2010. As discussed above, the contributions of the present proposal are: first, the alternatives for negative quantifiers proposed here make better predictions both for the case of scalar impli-

48 Notice that one could restrict also Chemla (2010) account to soft presuppositions. If one doesn't, however, one has to provide a different way to account for the differences between soft and hard presuppositions with respect to context dependence and projection (see Chemla 2010: p.41 for discussion). 
catures and for that of soft presuppositions from scopes and restrictors of negative quantifiers. Second, restricting the theory to soft presuppositions, we can account for the differences between them and hard presuppositions. Third, assuming a difference between scalar implicatures and soft presuppositions in terms of the notion of obligatory implicatures, we can, in turn, account for their different behavior.

\section{Appendix B: comparison with Fox 2012}

\subsection{A sketch of the theory}

Fox $(2008,2012)$ proposes a trivalent theory of presupposition projection, focusing in particular on how it can account for the complex pattern of projection of presuppositions embedded in the nuclear scope of quantificational sentences. For what is relevant here, I focus just on one aspect of the proposal by Fox (2012), namely the way he accounts for the differences between soft and hard presuppositions. ${ }^{49}$ Recall that there are two main differences a theory of presuppositions should account for: first, soft presuppositions appear to be easily suspendable in explicit ignorance contexts, while hard presuppositions do not. This is exemplified by (112a) and (112b).

a. I don't know whether John ended up participating in the race. But if he won, he will celebrate tonight.

b. I don't know whether anybody read that book. \#But if it was John, we should ask him what he thinks about it.

Second, as discussed, soft and hard presuppositions appear to project differently in quantificational sentences: while the latter uniformly project universally, the projection of the former depends on the quantifier involved (Chemla 2009b and Charlow (2009)). ${ }^{50}$

Fox's proposal for how to account for such differences is based on two ideas. The first idea is that presuppositions are suspended by the use of a local accommodation operator, the (A)ssertion-operator (Beaver \& Krahmer (2001)) ${ }^{51}$ I refer the reader

49 Fox $(2008,2012)$ also proposes a version of his account based on a bivalent, rather than trivalent, semantics, which reproduces and extends the predictions of the trivalent semantics account at the pragmatic level. For our purposes the differences between the two versions are not important, so I will disregard them here.

50 Fox (2012) also argues that there is another dimension of variation, which comes from individual differences among different speakers (see also Sudo et al. to appear). He furthermore proposes that we can account for the speaker's variability by assuming a preference with respect to whether a speaker is willing to locally accommodate or not. I will disregard this part of the proposal here and leave for further research how to account for speakers' variability in the account proposed here.

51 Fox (2012) calls it the "B" operator, as the original idea was proposed by the logician Dmitri Bochvar. 
The presuppositions of soft triggers are obligatory scalar implicatures

to Fox's (2012) for the details on the semantics of the $A$-operator, for our purposes here, it is enough to know that applying $A$ to a sentence $\phi$ with presupposition $p$ is equivalent to asserting the conjunction of $\phi$ and $p$. The idea is that a sentence like (113a) does not have the presupposition that Paul participated because it has an $A$-operator in the antecedent, which makes it equivalent to (113b).

\section{I don't know whether Paul participated or not.}

a. But If $\mathrm{A}[\mathrm{he}$ won], he will celebrate tonight.

b. But if he participated and won, he will celebrate tonight.

Furthermore, Fox (2012) shows that the $A$-operator can also account for the difference between quantifiers. His account predicts uniform universal projection of presuppositions (given a principle of presupposition strengthening), however through the use of the $A$-operator one can also account for the differences between quantifiers, in particular for the non universal projection in cases like (112b) above.

The second idea is that the difference between soft and hard presuppositions has to do with the fact that the former can be locally accommodated and the latter cannot. In the system he proposes, this means assuming a constraint along the lines of (114). ${ }^{52}$

52 As Fox (2012) acknowledges in fn.19, the condition that the A-operator cannot be applied to strong triggers cannot be as simple as (114). The problem is that we want to allow cases of suspension of soft presuppositions, even when a soft trigger is embedded into a strong one. For instance in (ia), where stop appears in the scope of also, we nonetheless need to insert the $A$ operator in order to suspend the presupposition of stop.

I know John stopped drinking. I don't know whether he used to smoke too.

a. $\quad$ But if he also stopped smoking, he must be very proud of himself.

b. But if A[he [also [stopped smoking]]], he must be very proud of himself.

Fox (2012) suggests that we co-index the A-operator with the soft trigger, the presupposition of which we want to locally accommodate. The constraint in (114) could be then modified as (ii).

(ii) The A-operator cannot be co-indexed with a strong trigger and applied to a constituent that contains it.

As I discuss in Romoli 2012, the indexing between the A-operator and its trigger is independently motivated, if we want to maintain an account of conflicting presuppositions in disjunctions via local accommodation, that is, if we want to analyze (iiia) as (iiib) (see Soames 1979, Heim 1983 and Beaver \& Krahmer (2001) for discussion).

(iii) a. John stopped smoking or he started smoking.

b. [A[John stopped smoking] or A[John started smoking]]

The argument for co-indexing the A-operator and its trigger comes from cases like (iv), where the only presupposition that we want to suspend is the one of stop and not the one of being upset (that 
The A-operator cannot be applied to constituents that contain a strong trigger.

As he shows, given (114) the system can account for the differences in suspension and projection between strong and hard presuppositions. In brief, (115) would be infelicitous because we cannot insert the A-operator and (116a) would only have the universal inference in (116b) for the same reason.

(115) I don't know whether anybody read that book. \#But if it was John, we should ask him what he thinks about it.
a. Some of these ten boys also smokes Marlboro.
b. Each of these ten boys smoke something other than Marlboro.

Let us now turn to a brief comparison between this system and the proposal outlined in this paper.

\subsection{Comparison}

The main point in favor of the account proposed in this paper regards the fact that it predicts that soft presuppositions project differently from the nuclear scope and from the restrictor of universal and negative quantifiers (cf. section 4). In particular, it predicts that (117a) can give rise to (117c), while (117b) cannot, in line with intuitions and the results in Chemla 2009b.

(117) a. No student in my class stopped smoking.

b. No student in my class who stopped smoking regrets it.

c. Every student in my class used to smoke.

Fox (2012) does not talk about the predictions of his system with respect to restrictors, but as far as I can see no difference is predicted between (117a) and (117b).

Finally, as Fox (2012) observes, under downward entailing operators like negation the reading in which the presupposition is locally accommodated is marked and it is felicitous only with a continuation that forces that reading.

(118) John didn't win the race. He didn't participated.

John left the country) or too (that somebody else salient left the country).

(iv) If either John stopped being upset that he left the country too or he started being upset that he left the country too, he will let us know soon. 
The presuppositions of soft triggers are obligatory scalar implicatures

Under the proposal here, the markedness of (118) follows with no extra assumptions from the independently motivated do not weaken! condition, repeated in (119). The reason is that in order to suspend (118) we need to exhaustify below negation, which is vacuous, thus against the condition in (119).

(119) Do not Weaken!: Do not insert EXH in a sentence $S$ if it leads to an equivalent or weaker meaning than $S$ without it.

Fox (2012: p.22-23) proposes two possible conditions on the insertion of the Aoperator, but they are not independently motivated like (119). ${ }^{53}$

\section{Appendix C: a note on van Rooij 2005, 2010}

Another approach to the soft-hard distinction can be found in the theory of presuppositions proposed in Rooij 2005, 2010. ${ }^{54}$ Building on Stalnaker (1970, 1973, 1974 , 1998, 2002), Rooij (2005, 2010) proposes an approach to presuppositions as propositional attitudes. What is relevant for us here is that this approach allows to treat the question of whether a sentence is true and that of whether its presuppositions are satisfied independently. This, in turn, can account for the cases of suspension of soft presuppositions discussed above: in this approach, those examples would be cases in which the presupposition is satisfied, but in an information state that does not represent what the speaker presuppose in the actual world. Moreover, one could assume that 'hard' presuppositions, instead, would be semantic presuppositions in the traditional sense, therefore not suspendable, unless extra mechanisms are adopted. ${ }^{55}$ In other words, the distinction between soft and hard presuppositions would be in terms of whether a presupposition is a propositional attitude, and thus could be satisfied independently of the truth of the sentence associated with it, or a

53 Both conditions he proposes can, however, account for another difference between the markedness of (118) and (i), which also needs the insertion of $A$ in his account, but that doesn't need a continuation in order to be felicitous.

(i) Some of our students won.

(i) is not a problem in the present account because it does not require exhaustification and it only gives rise to the existential inference that some of our students participated. Notice that, contrary to the system in Fox (2012), the proposal here does not predict that (i) can ever have a universal inference in (ii). It is unclear to me, however, that (i) can ever give rise to the inference in (ii).

(ii) Each of our students participated.

54 Thanks to Robert van Rooij (p.c.) for discussion on this.

55 Rooij $(2005,2010)$ argues that we should not adopt a mechanism of local accommodation or cancellation of presuppositions. 
more semantic one, which would then not be suspendable.

This approach is definitely worth exploring as an alternative solution to the difference and similarities problems delined above and I won't be able to do full justice to it within the limits of this paper. One question that arises immediately, however, is whether the differences in terms of projection can also be made to follow by this semantic presupposition vs. presupposition-as-propositional-attitude distinction, both for the cases of restrictors and scope of quantifiers. In other words, whether the non-uniform projection of soft presuppositions in quantificational sentences would follow from their being thought of as propositional attitudes. I leave a detailed comparison between this approach and the proposal in this paper for further research.

\section{References}

Abbott, Barbara. 2006. Where have some presuppositions gone? In Birner, Betty J. \& Gregory Ward (eds.), Drawing the Boundaries of Meaning: Neo-Gricean studies in pragmatics and semantics in honor of Laurence R. Horn, 1-33. John Benjamins.

Abrusán, Márta. 2011a. Predicting the presuppositions of soft triggers. Linguistics and Philosophy 34(6). 491-535.

Abrusán, Márta. 2011b. Triggering verbal presuppositions. In David Nan Li \& Lutz (ed.), Semantics and Linguistic Theory (SALT) 20, 684-701. Vancouver, British Columbia.

Abusch, Dorit. 2002. Lexical alternatives as a source of pragmatic presupposition. In Brendan Jackson (ed.), Semantics and Linguistic Theory (SALT) 12, 1-19.

Abusch, Dorit. 2010. Presupposition triggering from alternatives. Journal of Semantics 27(1). 1-44.

Beaver, David. 2001. Presupposition and Assertion in Dynamic Semantics. Stanford University: CSLI Publications.

Beaver, David. 2010. Have you noticed that your belly button lint colour is related to the colour of your clothing? In Rainer Bauerle, Uwe Reyle \& Thomas Ede Zimmerman (eds.), Presuppositions and discourse: Essays offered to Hans Kamp, Crispi.

Beaver, David \& Emil Krahmer. 2001. A partial account of presupposition projection. Journal of Logic, Language and Information 10(2). 147-182.

Charlow, Simon. 2009. "Strong" predicative presuppositional objects. In Proceedings of ESSLLI 2009, Bordeaux.

Chemla, Emmanuel. 2008. An anti-introduction to presuppositions. In Paul Egré \& Giorgio Magri (eds.), Presuppositions and Implicatures: Proceedings of 
The presuppositions of soft triggers are obligatory scalar implicatures

MIT-France Workshop on Scalar Implicature and Presupposition, vol. 60, MIT Working Papers in Linguistics.

Chemla, Emmanuel. 2009a. Presuppositions of quantified sentences: experimental data. Unpublished previous version of Chemla 2009b available at http://www.emmanuel.chemla.free.fr.

Chemla, Emmanuel. 2009b. Presuppositions of quantified sentences: Experimental data. Natural Language Semantics 17(4). 299-340.

Chemla, Emmanuel. 2010. Similarity: towards a unified account of scalar implicatures, free choice permission and presupposition projection. Unpublished manuscript.

Chemla, Emmanuel \& Lewis Bott. 2013. Processing presuppositions: Dynamic semantics vs pragmatic enrichment. Language and Cognitive Processes 38(3). 241-260.

Chierchia, Gennaro. 2004. Scalar implicatures, polarity phenomena, and the syntax/pragmatics interface. In Adriana Belletti (ed.), Structures and Beyond: The Cartography of Syntactic Structures, vol. 3, 39-103. Oxford: Oxford University Press.

Chierchia, Gennaro. in press. Logic in grammar: Polarity, free choice, and intervention. Oxford University Press.

Chierchia, Gennaro, Danny Fox \& Benjamin Spector. in press. The grammatical view of scalar implicatures and the relationship between semantics and pragmatics. In Claudia Maienborn, Klaus von Heusinger \& Paul Portner (eds.), Semantics: An international handbook of natural language meaning volume 3, Berlin: Mouton de Gruyter.

Chierchia, Gennaro \& Sally McConnell-Ginet. 2000. Meaning and Grammar: An Introduction to Semantics, 2nd edition. Cambridge: MIT Press.

Doron, Edit. 1983. Verbless predicates in hebrew: University of Texas at Austin dissertation.

von Fintel, Kai. 1995. The formal semantics of grammaticalization. In Jill Beckman (ed.), North east linguistic society, 175-190. University of Pennsylvania: Graduate Linguistic Student Association.

Fox, Danny. 2007. Free choice and the theory of scalar implicatures. In Uli Sauerland \& Penka Stateva (eds.), Presupposition and Implicature in Compositional Semantics, 71-120. Palgrave.

Fox, Danny. 2008. Two short notes on schlenker's theory of presupposition projection. Theoretical Linguistics 34(3). 237-252.

Fox, Danny. 2012. Presupposition projection from quantificational sentences: trivalence, local accommodation, and presupposition strengthening. MS the Hebrew University of Jerusalem.

Fox, Danny \& Roni Katzir. 2011. On the characterization of alternatives. Natural 
Language Semantics 19(1). 87-107.

Fox, Danny \& Benjamin Spector. 2009. Economy and embedded exhaustification. Talk given at Cornell University.

Franke, Michael. 2010. Signal to act: game theory in pragmatics: Universiteit van Amsterdam dissertation.

Gazdar, Gerald. 1979. Pragmatics: Implicature, Presupposition, and Logical Form. New York: Academic Press.

George, Benjamin. 2008. Presupposition repairs: a static, trivalent approach to predicting projection: UCLA MA thesis.

Geurts, Bart. 1995. Presupposing: University of Stuttgart dissertation.

Geurts, Bart. 1999. Presuppositions and Pronouns. Elsevier North-Holland, Inc.

Groenendijk, J. \& M. Stokhof. 1982. Semantic analysis of wh-complements. Linguistics and Philosophy 5. 173-233.

Heim, Irene. 1983. On the projection problem for presuppositions. In Daniel P. Flickinger (ed.), Proceedings of WCCFL 2, 114-125. Stanford University, Stanford, California: CSLI Publications.

Heim, Irene. 2011. Lecture notes. Pragmatics Class, MIT.

Horn, Lawrence. 1972. On the semantic properties of logical operators in English: UCLA dissertation.

Hurford, James R. 1974. Exclusive or inclusive disjunction. Foundations of Language 11. 409-411.

Iatridou, Sabine \& Ivy Sichel. 2008. Negative DPs and scope diminishment: Some basic patterns. In Proceedings of NELS 38, .

Karttunen, Lauri. 1971. Some observations on factivity. Papers in Linguistics 4. 55-69.

Kempson, Ruth. 1975. Presupposition and the delimitation of semantics. Cambridge University Press.

Klinedinst, Nathan. 2010. Totally hardcore semantic presuppositions. Unpublished manuscript.

Levinson, Stephen. 2000. Presumptive meanings. MIT Press.

Magri, Giorgio. 2010. A theory of individual-level predicates based on blind mandatory scalar implicatures: Massachusetts Institute of Technology dissertation.

Magri, Giorgio. 2011. Another argument for embedded scalar implicatures based on oddness in DE environments. Semantics and Pragmatics 4(6). 1-51.

Panizza, Daniele, Gennaro Chierchia \& Jr. Clifton, Charles. 2009. On the role of entailment patterns and scalar implicatures in the processing of numerals. Journal of Memory and Language .

Penka, Doris. 2007. Negative indefinites: Universität Tübingen dissertation.

Perez-Carballo, Alessandro. 2008. Toward a dissolution of the proviso problem. In Paul Egré \& Giorgio Magri (eds.), Presuppositions and Implicatures: Pro- 
The presuppositions of soft triggers are obligatory scalar implicatures

ceedings of MIT-France Workshop on Scalar Implicature and Presupposition, vol. 60, MIT Working Papers in Linguistics.

Romoli, Jacopo. 2011. The presuppositions of soft triggers aren't presuppositions. In Neil Ashton, Anca Chereches \& David Lut (eds.), Semantic and linguistic theory (SALT) 21, Rutgers University.

Romoli, Jacopo. 2012. Soft but strong: Neg-raising, soft triggers, and exhaustification: Harvard University dissertation.

Romoli, Jacopo. to appear. A scalar implicature-based approach to Neg-raising. Linguistics and philosophy .

Rooij, Robert van. 2005. A modal analysis of presuppositions and modal subordination. Journal of Semantics 22(3). 281-306.

Rooij, Robert van. 2010. Presupposition: an (un)common attitude? In Rainer Bauerle, Uwe Reyle \& Thomas Zimmermann (eds.), Presuppositions and discourse: Essays offered to hans kamp, 1-27. Brill.

Rooth, Mats. 1992. A theory of focus interpretation. Natural Language Semantics 1(1). 117-121.

Sauerland, Uli. 2000. No 'no': on the crosslinguistic absence of a determiner 'no'. In Proceedings of the tsukuba workshop on determiners and quantification, Tsukuba University, Tsukuba, Japan.

Sauerland, Uli. 2004. Scalar implicatures in complex sentences. Linguistics and Philosophy 27(3). 367-391.

Sauerland, Uli. 2008. Implicated presuppositions. In Anita Steube (ed.), Sentence and context: Language, context and cognition., Berlin and new York: Mouton de Gruyter.

Schlenker, Philippe. 2008. Presupposition projection: the new debate. SALT proceedings .

Schlenker, Philippe. 2010. Local contexts and local meanings. Philosophical Studies 151(1). 115-142.

Simons, Mandy. 2001. On the conversational basis of some presuppositions. In Rachel Hastings, Brendan Jackson \& Zsofia Zvolenszky (eds.), Semantics and Linguistic Theory (SALT) 11, 431-448.

Simons, Mandy, David Beaver, Craige Roberts \& Judith Tonhauser. 2010. What projects and why. SALT proceedings .

Singh, Raj. 2008a. Modularity and locality in interpretation: Massachusetts Institute of Technology dissertation.

Singh, Raj. 2008b. On the interpreation of disjunction: asymmetric, incremental and eager for inconsistency. Linguistics and Philosophy 31. 245-260.

Singh, Raj. 2009. Symmetric and interacting alternatives for implicature and accommodation. Ms MIT.

Soames, Scott. 1979. A projection problem for speaker presuppositions. Linguistic 
Inquiry 10(4). 623-666.

Spector, Benjamin. 2007. Aspects of the pragmatics of plural morphology: On higher-order implicatures. In Uli Sauerland \& Penka Stateva (eds.), Presupposition and implicature in compositional semantics, Palgrave.

Stalnaker, Robert. 1970. Pragmatics. Synthese .

Stalnaker, Robert. 1973. Presuppositions. Journal of Philosophical Logic (2). 447-457.

Stalnaker, Robert. 1974. Pragmatic presuppositions. In M. Munitz \& D. Unger (eds.), Semantics and philosophy, 197-213. New York University Press.

Stalnaker, Robert. 1998. On the representation of context. In Teresa Galloway \& Justin Spence (eds.), Proceedings of SALT VI, 279-294. Ithaca, NY: CLC Publications.

Stalnaker, Robert. 2002. Common ground. Linguistic and Philosophy .

Sudo, Yasutada, Jacopo Romoli, Danny Fox \& Martin Hackl. to appear. Variation of presupposition projection in quantified sentences. In Proceedings of the amsterdam colloquium 2011, Amsterdam, The Netherlands.

van der Sandt, Rob. 1992. Presupposition projection as anaphora resolution. Journal of Semantics 9. 333-377.

van Rooij, Robert. 2002. Relevance implicatures. MS, ILLC, Amsterdam.

van Rooij, Robert. 2007. Strengthening conditional presuppositions. Journal of Semantics 24(3). 289-304.

van Rooij, Robert \& Katrin Schulz. 2004. Pragmatic meaning and non-monotonic reasoning: The case of exhaustive interpretation. Linguistics and Philosophy .

von Fintel, Kai. 1999. Counterfactuals in dynamic contexts. In Uli Sauerland \& Orin Percus (eds.), The Interpretive Tract, 123-152. MIT Working Papers in Linguistics.

von Fintel, Kai. 2004. 'would you believe it? the king of france is back! presuppositions and truth-value intuitions". In Descriptions and Beyond, edited by Marga Reimer and Anne Bezuidenhout. Oxford University Press. .

von Fintel, Kai. 2008. What is accommodation, again? Philosophical Perspectives, 22, Philosophy of Language .

Wagner, Michael. 2012. Focus and givenness: a unified approach. In Ivona Kučerová (ed.), Contrasts and positions in information structure, Cambridge University Press.

Wilson, Deirdre. 1975. Presupposition, assertion, and lexical items. Linguistic Inquiry 6(1). 95-114.

Zondervan, Arjen. 2009. Experiments on qud and focus as a contextual constraint on scalar implicature calculation. In Uli Sauerland \& Kazuko Yatsushiro (eds.), From experiment to theory, presuppositions, negation and scalar implicatures, Palgrave. 